\title{
Seasonal Spatial and Temporal Distribution of Chlorophyll- $a$ Concentration over Kuwait and the Arabian Gulf using Satellite and In-Situ Data
}

\author{
Jasem A. Albanai ${ }^{1,2}$ \\ ${ }^{1}$ Marine Monitoring Section, Water Quality Monitoring Department, Environmental Public \\ Authority, Kuwait \\ 2 Charmin's office, Public Authority for Agriculture Affairs and Fish Resources (PAAF), \\ Kuwait
}

\begin{abstract}
The concentration of chlorophyll- $a$ (chlor- $a$ ) is an important indicator of marine water quality, as it is considered an indicator of the phytoplankton density in a specific area. Remote sensing techniques have been developed to measure the near-surface concentration of chlor- $a$ in water across the correlation between spectral bands and in situ data. This algorithm applies to sensors of varying spatial, temporal and spectral resolutions. However, in this study, chlor- $a$ level 2 and 3 products of SNPP - VIIRS spectrometer (Equation OC3) of NASA OceanColor suite was relied upon to study the spatial and temporal distribution of chlor- $a$ concentration in the Arabian Gulf (also known as the Persian Gulf) and the State of Kuwait's water (located to the north-eastern part of the Arabian Gulf) from 2012 to 2019. Ground truthing points $(n=192)$ matched to the level 2 products have been used to build an empirical model and cross-validate it. The correlation was positive where $r^{2}$ was 0.79 and the validation RMSE was $= \pm 0.64$ $\mathrm{mg} / \mathrm{m}^{-3}$. The derived algorithm was then applied to chlor- $a$ level 3 seasonal products. Additionally, the chlor- $a$ concentration values of Kuwaiti waters have been enhanced using the IDW algorithm to increase the spatial resolution, as it is considered as a small area compared to the spatial resolution of level 3 chlor- $a$ products. The model derived from IDW was tested using the Mann Whitney test ( $\operatorname{Sig}=0.948 \mathrm{p}<0.01$ ). However, the result showed that the chlor$a$ concentration is higher in Kuwait Bay compared to Kuwaiti water, and it is higher in Kuwaiti water compared to the Arabian Gulf. The coasts have higher concentrations too, when compared to the open water. Generally, the chlor- $a$ increases in winter and makes a semiregular cycle during the years of study; this cycle is more regular in the Gulf's waters than in Kuwait's.
\end{abstract}

Keywords: Kuwait, Arabian Gulf, Remote Sensing, ChlorophyII- $a$, Marine Biogeography

\section{Introduction}

The water quality of seas and oceans is determined by their physical, chemical and biological properties, such as sea temperature, salinity, dissolved oxygen, $\mathrm{pH}$ and chlor- $a$ concentration, among others. One of the most valuable approaches in studying water quality is the analysis of the temporal and spatial distribution of marine variables, and the measurement of the changes in these patterns. Chlor- $a$ concentration can be used as an indicator of the density of phytoplankton [1], which can in turn help to monitor and assess the marine resources and water quality [2]. Remote sensing techniques have been widely used to obtain marine quality parameters [3-7]. Chlor- $a$ data can be obtained systematically from remote sensing instruments 
over large geographic areas, rather than through the use of field-point observations [8]. Statistical methods have been used extensively throughout previous literature to describe and analyse the temporal and spatial distribution of marine water quality parameters through remote sensing methods and field surveys $[9,10]$. Several methods have been used to determine chlor$a$ concentrations from space. While some focus on stationary variation, such as using the Empirical Orthogonal Function [9] which analyses the spatio-temporal variation with a set of orthogonal functions, others focus on non-stationary variation methods [11, 12], which highlight the sudden changes that happen due to abnormal events [13], more often than not controlled by hydrodynamics, bathymetry, stratification, mixing processes and nutrient uptake $[14,15]$. Therefore, both stationary and non-stationary variations help increase our understanding of the spatial and temporal distribution of chlor- $a$ concentration [13].

Studies to extract marine environment parameters from satellites in the Arabian Gulf are few and far between, despite their global relevance and importance. This can mainly be put down to the dust storms that obstruct remote sensing instruments $[16,17]$, the lack of quality in-situ measurements, the complex sea-river environments that occur here [2] and the limited spatial coverage of many global remote sensing products over the marginal seas of the Arabian Gulf. However, the general water circulation, bathymetry and hydrodynamics in the Arabian Gulf have been discussed and analysed by numerous authors [17-20]. Nezlin et al. [21] divided the Gulf into regions based on its oceanographic properties and water circulation [18]; here, the chlor- $a$ concentration was estimated to be much higher towards the north of the Gulf. Lately, remote sensing instruments have been widely used to obtain near-surface chlor- $a$ concentrations, measured by moderate spatial resolution satellites provided by NASA through the correlation of blue-to-green spectral range and in-situ data [22]. As to the benefits of remote sensing methods, O'Reilly et al. [23] showed that remote sensing could be affected by the bottom reflection and the high turbidity. The NASA OceanColor products were developed to measure chlor- $a$ in the open oceans, where the water color results mainly from the chlor- $a$ concentration [23]. The Arabian Gulf is classed as a marginal water, influenced by the discharge of both the Tigris and Euphrates, which means that the chlor- $a$ concentration is affected by the concentrations of both the dissolved and the suspended matter [24]. In such circumstances, regional models for the Arabian Gulf give more accurate results [21].

Nezlin et al. [17] derived the monthly chlor- $a$ concentration, and analysed the environmental factors related to phytoplankton distribution. The study showed that the chlor- $a$ concentration peaks in August and October, while it is at its minimum in February and March. The fieldbased measurements of chlor- $a$ show that the concentration ranges from 0.01 to $10 \mathrm{mg} / \mathrm{m}^{-3}$ in the Arabian Gulf [20], while it may reach up to 55.4 to $4525 \mathrm{mg} / \mathrm{m}^{-3}$ in abnormal bloom conditions in the northwest of the Gulf [25]. Moradi and Kabiri [13] studied the spatial and temporal variation of chlor- $a$ from 2002 to 2013 using MODIS data. Their study showed that the stationary level of chlor- $a$ concentration is higher in coastal areas, while the temporal peaks can be noticed in summer and winter in the north-western region. However, the accuracy of VIIRS and other merged satellites sensors' datasets in measuring chlor- $a$ concentration were validated positively in the Arabian Gulf by Al-Naimi et al. [2] through ground truthing points taken in the mid-west of the Gulf. Additionally, Zhao et al. [26] developed and tested the red tide index over the Arabian Gulf using the MODIS Aqua satellite sensor, while Polikarpov et al. [27] discussed the phytoplankton variability over the Arabian Gulf, also using the MODIS Aqua satellite sensor.

As for the northern reaches of the Arabian Gulf, where the territorial water of Kuwait can be found in the west. Studies looking at the spatial and temporal distribution of chlor- $a$ concentration are limited to Al-Yamani et al.'s study [28]. In their comprehensive analysis of 
Kuwait's marine environment, the authors show the spatio-temporal variation of chlor- $a$ in Kuwaiti waters based on field measurements from Kuwait Environmental Public Authority. The study showed that chlor- $a$ has a decreasing concentration from north to south, where the concentration is much higher in the north and in Kuwait Bay during the winter and early spring. With the small number studies of Kuwait's waters specifically, there is a need to clarify the spatio-temporal difference. Therefore, this study aims to increase our understanding of the spatio-temporal chlor- $a$ distribution based on empirical spatial enhancements of VIIRS - SNPP data for Kuwait's water as a part of the Arabian Gulf. The distribution and dynamics of chlor$a$ concentration in Kuwaiti waters is the key indicator towards understanding the density of phytoplankton, as well as Kuwait's marine ecosystem environment, from both a spatial and a temporal perspective. Additionally, VIIRS is seen as a MODIS successor in providing geophysical data with higher spatial resolution [29, 30]. The two sensors differ slightly from the green, blue and red spectral bands used in the final products of NASA OceanColor [31]. However, among several studies, VIIRS showed a lower average error than MODIS in measuring chlor- $a$ concentration, using an OC3 algorithm, across different regions of the world (including the Gulf of Gabes, the northern South China Sea, the Red Sea, the California Current Bed and the Arabian Gulf) [2, 32-35]. Therefore, using VIIRS on the North Arabian Gulf will increase our understanding of the satellite response in order to obtain measurements for both chlor- $a$ concentration and phytoplankton density.

\section{Study area}

\subsection{Arabian Gulf}

The Arabian Gulf (also known as the Persian Gulf) is a shallow marginal sea of the Indian Ocean (Fig. 1). It is located between the Arabian Peninsula and south-western Iran. The Gulf is located between $23.5^{\circ}$ and $30.05^{\circ}$ North and $47.5^{\circ}$ and $56.4^{\circ}$ East, with a length and width of approximately $56-338 \mathrm{~km}$ respectively, covering a total surface area of $240,000 \mathrm{~km}^{2}$ [27, $28,36]$. The total water volume in the Gulf is estimated to be roughly $6000 \mathrm{~km}^{3}$ [13]. The Gulf is relatively shallow, with the deepest point reaching just over $100 \mathrm{~m}$, while the average depth is about $35 \mathrm{~m}$. The main source of fresh water is from the Shatt al-Arab deltaic system (the delta of Tigris, Euphrates and Karun rivers) to the northern end of the Gulf. The maximum discharge occurs during late spring and early summer [28]. The amounts that the main northern rivers discharge to the Gulf annually is estimated to be $1.1 * 10^{8} \mathrm{~m}^{3}$ of water and $4.8 * 10^{6}$ tonnes of sediment [18]. The Gulf is connected to the Arabian Sea and the Indian Ocean through the Strait of Hormuz, allowing the water to exchange in a slow circulation [37]. The mean hydrodynamic circulation is counter-clockwise cyclonic, forced with the inflowing currents to the north and of the Gulf in summer, and weakened by the north-westerly winds along the Iranian coast in winter [18]. The Arabian Gulf has a subtropical hyper-arid climate and is surrounded by desert lands, where the precipitation levels are relativity limited [28], and the evaporation rate is estimated by numerous authors to be very high (1.44 - $\left.1.64 \mathrm{~m} \mathrm{year}^{-1}\right)$ [38].

The physiochemical properties of the Gulf's water reflect the shallowness, high evaporation, limited freshwater river runoff and low rainfall. The sea surface temperature reaches a maximum of roughly $36{ }^{\circ} \mathrm{C}$ and a minimum of $14{ }^{\circ} \mathrm{C}$. The Arabian Gulf is considered as one of the most saline basins in the Earth. The salinity concentration ranges from about 35 to 40 PSU, reaching 70 PSU in some shallow south-eastern embayments $[2,18,27]$. The deeper parts of the Gulf have an evident saline stratification, while the shallows are well mixed by both the wind and current systems. The north-westerly winds and south-eastward coastal currents cause the upwelling along the eastern Iranian coasts and downwelling along the western Arabian 
coasts [18]. The recent study of Al-Yamani and Naqvi [39] showed that the salinity has increased in the northern area of the Gulf because of the reduction of river runoff. The Gulf is one of the main sources of aeolian dust deposits in the world [40]. Belt dust storms intensify in the summer, along the north-western winds, while these strong dust-laden winds ease in the winter [16, 17]. The biological productivity in the Arabian Gulf is highly related to the geographical distribution of nutrients [27]. The limited upwelling conditions in the Gulf result in a limited nutrient concentration in most offshore Gulf waters [38]; by contrast, some coastal river-discharge-influenced areas are much higher in concentration [41]. However, a significant increase in nutrients has been identified, caused chiefly by the sewage discharge from the urban coastal areas along the coasts of the Gulf. Recently, the anthropogenic stresses have been cited as one of the biggest challenges facing the marine ecological environment of the Arabian Gulf [39]. Nezlin et al. [21] has divided the Gulf into regional sub-basins according to their properties, and a more recent study by Polikarpov et al. [27] sought to modify this partition (Fig. 1). The Arabian Gulf is of great economic and international importance due to the oil movement through the Strait of Hormuz [42], in addition to the highly productive ecosystems that the Gulf has [27].

\subsection{Kuwait}

Kuwait is a state located on the north-western corner of the Arabian Gulf, surrounded by Saudi Arabia to the south and west, and Iraq to the North. Kuwait is part of the Arabian desert and is considered one of the warmest regions in the world. The temperature in the summer reaches above $50{ }^{\circ} \mathrm{C}$, while it drops to about $7{ }^{\circ} \mathrm{C}$ in the winter. The topography of Kuwait plays a role in its drought, as its lands are considered flat; the elevation rises from sea level on the eastern coasts to the highest point in the south-east of its territory, reaching up to 280 meters above sea level [43]. The water of Kuwait is considered as a part of the submerged northern estuarine flat of the Arabian Gulf (Fig. 1), which is mainly affected by the sea-river environment of Shatt alArab [28]. The length of the State of Kuwait's coastline extends to more than $700 \mathrm{~km} \mathrm{[44].}$ This length has, in recent years, been increased due to various development projects and the creation of artificial beaches. Kuwait has nine islands. Physiographically, these islands can be classified into two groups: coastal and offshore [28]. The coastal group has six islands located in the north of the country's territorial water. These are Warba, Bubyan, Miskan, Failaka, Awhah and Umm Al-Namil. A narrow channel called Khor Al-Sabbiya separates Bubyan and Warba from the mainland of the State of Kuwait. The rest of the islands are located in the southern water of the country, including Kubber, Qaruh and Amm Al-Maradim.

Kuwait's territorial waters covering an area of about 8,000 square kilometres, contain three main sub-regions: Kuwait Bay, the northern waters, and the southern waters. Kuwait Bay is located in the middle of the country's coastline. The bay is shallow, with an average depth of about five meters; a slow counterclockwise circulation appears in Kuwait Bay throughout much of the year while, in winter, the circulation is significantly reversed due to the south-easterly predominate [28]. Kuwait Bay has other different sub-circulation patterns such as the net clockwise drift in the western side and the counter-clockwise pattern in the eastern side [45]. As for the northern region, it is characterized by a narrow channel surrounding Warba and Bubyan islands, which makes the currents the main hydrodynamic factor in the region [46]. The maximum current speeds were observed in Khor Al-Subbiya (reaching 1.2 meters $s^{-2}$ ) [28]. The northern water is a part of the submerged northern estuarine flat, while the southern waters are more identical to those of the open Arabian Gulf [28]. Here, the depth increases to a maximum of about 30 meters, making the average depth of Kuwaiti waters about 20 meters 
[28]. Kuwait's territorial waters have an average sea surface temperature of $23.8^{\circ} \mathrm{C}$ and salinity of around 40 PSU [28].

\section{Methodology}

\subsection{In Situ data}

The field data used referred to Kuwait Environmental Public Authority (KEPA) (epa.org.kw). KEPA has a data archive spanning back to 1983 for Kuwait's marine environment. In 2016, KEPA established a marine monitoring system using 15 buoys spread across Kuwaiti territorial waters (Fig. 1). Three buoys are located in the northern waters (S1 -S3), five are in Kuwait Bay (S4 - S8), while the rest can be found in the southern waters (S9-S15). The buoys coordinates can be found on KEPA website. The archive comprises data of multiple water quality parameters such as sea surface temperature, salinity, conductivity and turbidity, dissolved oxygen and $\mathrm{pH}$. The chlor- $a$ were measured by Turner CYCLOPS-7 (Model SEN-CHA-XAN06) sensor. Instruments are yearly calibrated and periodically once in 15-30 days after the field visit. Calibration done according to NIST standard. Readings are taken every 10 minutes daily between half meter to one meter from the water surface. There were some malfunctions at times with the instrument, causing some gaps in readings.

The chlor- $a$ data as monitored by the 15 buoys at 10:00 - 11:00 AM (hourly average) throughout 2017 has been used in the study as ground truthing points (GTPs). Additionally, turbidity data (measured by AML oceanographic sensor model XCH-TRB-A3000-02W) were used to understand the optical properties in different studied areas of the Kuwait's waters, and a bathymetric layer obtained from the admiralty chart of Kuwait territorial waters referred to the ministry of defence and ministry of communications archived by KEPA was used to show the bathymetry of Kuwait territorial waters.

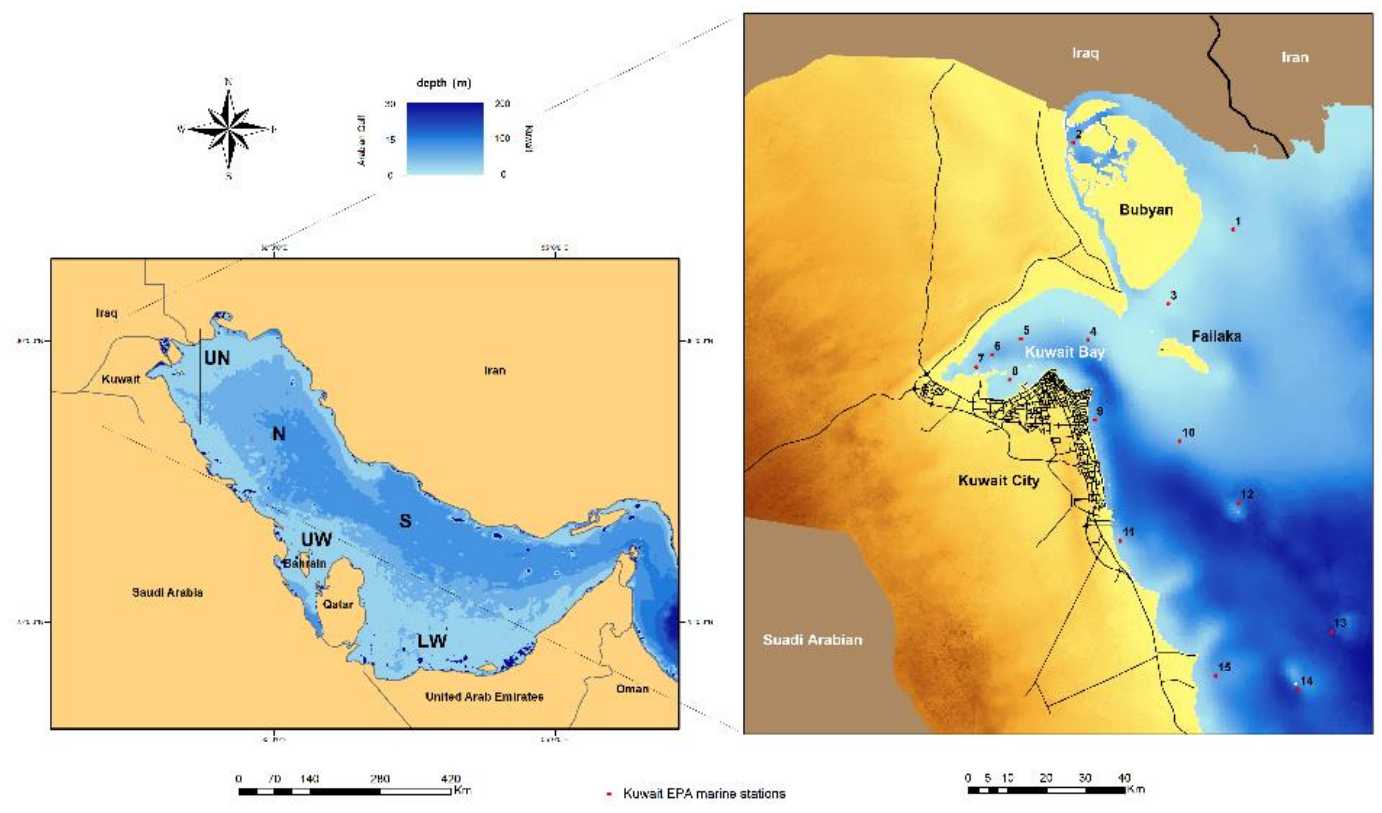

Fig. 1. The Arabian Gulf (with sub-basin regions): the upper coastal Northern Shatt Al-Arab zone (UN), the northern open water $(\mathrm{N})$, the southern open water $(\mathrm{S})$, upper coastal western Saudi Arabian zone (UW), and the lower shallow water between Qatar and UAE including Bahrain's coasts (LW). On the right are the locations of the Kuwait water and Environmental Public Authority marine buoys. After Polikarpov et al. [27] with modifitions. 


\subsection{Satellite data}

The data used are downloaded from the OceanColor website (oceancolor.gsfc.nasa.gov). NASA OceanColor is a platform supported by the Ocean Biology Processing Group (OBPG) at NASA's Goddard Space Flight Center. Since 1996, NASA has provided the scientific society with different products that relate to the marine environment and water quality, using satellite data. The products are divided into levels. Generally, level 1 and 2 data contain full-resolution, time-referenced and radiometrically- and geometrically-calibrated data and derived geophysical variables such as sea surface temperature and chlor- $a$ concentration. On the other hand, level 3 data contain time-derived geophysical variables for a specific period (monthly, annually etc.). The OceanColor website provides data for several sensors such as SeaWiFS, Aquarius, MODIS and VIIRS. The Visible and Infrared Imager/Radiometer Suite (VIIRS) is a spectrometer carried by the Suomi National Polar-orbiting Partnership (S-NPP) launched in October 2011, which is being orbited on the Joint Polar Satellite System (JPSS). VIIRS is a moderate-resolution spectrometer that has 22 spectral bands, ranging from $412 \mu \mathrm{m}$ to $12 \mu \mathrm{m}$; 16 bands have a spatial resolution of $750 \mathrm{~m}$ at their lowest, while five image resolution bands have a spatial resolution of $375 \mathrm{~m}$, and there is one day-night band (DNB) [29, 30]. The geophysical variables of near-surface concentration of chlor- $a$ in $\mathrm{mg} / \mathrm{m}^{-3}$ of the spectrometer are obtained using an empirical correlation between the blue to green bands ratios of spectral reflections depending on two to four bands, ranging between 440 and $570 \mu \mathrm{m}$, and the in-situ measurements [31]. The band ratios algorithm of J. E. O'Reilly et al. [22] was merged with a prior water index algorithm of C. C. Hu, Z. Lee, and B. Franz [47] to produce the final product provided by NASA. C. Hu, Z. Lee, and B. Franz [47] clearly shown that the improvement is limited to relativity clear water. Upon application, the algorithm differs slightly from what was published in their paper. That happens because the transition between water color index (CI) and band rationing algorithm (OCx) now occurs at $0.15<\mathrm{CI}<0.2 \mathrm{mg} / \mathrm{m}^{-3}$ to ensure a smooth transition [31]. The current chlor- $a$ product is based on the following algorithms:

$$
C I=R_{\text {rs }}\left(\lambda_{\text {green }}\right)-\left[R_{\text {rs }}\left(\lambda_{\text {blue }}\right)+\frac{\left(\lambda_{\text {green }}-\lambda_{\text {blue }}\right)}{\left(\lambda_{\text {red }}-\lambda_{\text {blue }}\right)} *\left(R_{\text {rs }}\left(\lambda_{\text {red }}\right)-R_{\text {rs }}\left(\lambda_{\text {blue }}\right)\right)\right]
$$

(Equation 1)

Where $R_{r s}$ ( $\lambda$ blue, $\lambda$ green and $\lambda$ red) are the spectral bands in the closest wavelength to 443 , 555 and $670 \mathrm{~nm}$ respectively, $\mathrm{CI}$ is the color index.

$$
\log _{10}(\text { chlor }-a)=a_{0}+\Sigma_{i=1}^{4} a_{i}\left(\log _{10}\left(\frac{\left(R_{r s}\left(\lambda_{\text {blue }}\right)\right.}{\left(R_{r s}\left(\lambda_{\text {green }}\right)\right.}\right)\right)^{i}
$$

(Equation 2)

Where the numerator, $R_{r s}$ ( $\lambda$ blue), is the greatest of several inputs $R_{r s}$ values and the coefficients, a 0 -a 4 , are sensor-specific (0.2424 and -1.2280 for MODIS, and 0.2228 and -0.7768 for VIIRS (OC3) respectively, chlor- $a$ is the output of chlor- $a$ concentration in $\mathrm{mg} / \mathrm{m}^{-3}$. 
The water color index algorithm is used for chlor- $a$ concentration below $0.15 \mathrm{mg} / \mathrm{m}^{-3}$, while the band rationing algorithm is used for concentrations above $0.2 \mathrm{mg} / \mathrm{m}^{-3}$. between these two values, both algorithms are combined using a weighted method [31].

In this study, 45 levels 2 VIIRS (SNPP) chlor- $a$ concentration products were downloaded from the OceanColor website for the Arabian Gulf region. The data cover all twelve months of 2017. The pixel size of level 2 data is 1 square $\mathrm{km}$, and the temporal resolution is daily. On the other side, 64 seasonal level 3 VIIRS (SNPP) chlor- $a$ concentration products for the Arabian Gulf were ordered and used. The data cover eight years from 2012 until 2019 with one product covering each season (4 products for each year). This means that one product constitutes the geophysical mean values of about 30 daily images. So, the level 3 data used in this study refers to more than 2929 analysed chlor- $a$ daily level 2 products. The spatial resolution of the level 3 products comes in at 4 and 9 square $\mathrm{Km}$. The $4 \mathrm{~km}$ product was used. The reason for choosing the 2017 level 2 products is for calibration and verification using KEPA GTPs, while the spatial and temporal differences and coverage are the reason for choosing level 3 data.

\subsection{Prediction and validation}

Although the chlor- $a$ products of VIIRS - SNPP is modelled using in-situ data [29], and many studies have demonstrated the accuracy of these data $[2,35]$, the products must be validated locally. The correlation between satellite and the near-surface chlor- $a$ concentration may be affected by several local properties, broadly speaking controlled by the geographical and oceanographical conditions [8]. Therefore, GTPs $(n=192)$ observed by 15 stations covering all Kuwaiti water were used to build a new empirical local model and validate it. Linear regression analysis was used to build the model regarding the correlation between GTPs and satellite level 2 chlor- $a$ products (OC3). The following matrix was used to compute the regression algorithm:

$$
\left[\begin{array}{c}
\text { Chlor }-a_{1} \\
\text { Chlor }-a_{2} \\
\cdot \\
\cdot \\
\cdot \\
\text { Chlor }-a_{n}
\end{array}\right]=\left[\begin{array}{cc}
\beta_{0}+\beta_{1} & \text { Raster }_{1} \\
\beta_{0}+\beta_{1} & \text { Raster }_{2} \\
\cdot & \cdot \\
\cdot & \\
\beta_{0}+\beta_{1} & \text { Raster }_{n}
\end{array}\right]+\left[\begin{array}{c}
\epsilon_{1} \\
\epsilon_{2} \\
\cdot \\
\cdot \\
\cdot \\
\epsilon_{n}
\end{array}\right]
$$

(Equation 3)

Where $\beta_{0}$ and $\beta_{1}$ are population chlor- $a$ intercept and population slope coefficient. raster is the chlor- $a$ (OC3) product at specific points and $\epsilon$ is the random error. Chlor $-a$ is the predicted output of Chlor- $a$ values.

A window of $3 * 3$ pixels was built around each GTP to extract the satellite data for matching. This technique was applied in previous studies too [43, 48]. The satellite data that have a standard deviation of more than $3 \mathrm{mg} / \mathrm{m}^{-3}$ were avoided in the analysis regarding matching 
accuracy. The GTPs were divided into two groups: GTPs $(n=113)$ monitored in three seasons (spring, summer and fall) were used to find the correlation and build the model, and those $(\mathrm{n}=$ 79) observed in winter were used to validate the predicted model (through a seasonal crossvalidation process). The correlation was positive where $r^{2}=0.792$ (Fig. 2 and Fig. 3). To give more credibility to the extracted model, the index of agreement (d) was calculated. The index has been previously proposed by Willmott [49], in order to evaluate the geographical models. The index can measure the error of predication models, ranging on a scale between 0 and 1 , where 1 indicates a perfect correlation, while 0 means no agreement at all. However, because of the squared differences, the index is sensitive to outliers. The (d) index can be computed as follows:

$$
d=1-\frac{\sum_{i=1}^{n}\left(x_{i}-y_{i}\right)^{2}}{\sum_{i=1}^{n}\left(\left(\left|y_{i}-\bar{x}_{i}\right|\right)+\left(\left|X_{i}+\bar{x}_{i}\right|\right)\right)^{2}}
$$

(Equation 4)

Where $x_{i}$ and $y_{i}$ are the observation and forecast values respectively.

The accuracy of the empirical regression model was examined through the root mean square error (RMSE) and the mean absolute error (MAE). These two indices are used to determine the correlation between two variables quantitively. These indices were used in several similar studies $[39,50,51]$. The RMSE and MAE are computed using the following formulas:

$$
R M S E= \pm \sqrt{\frac{1}{n} \sum_{i=1}\left(f_{i}-f_{j}\right)^{2}}
$$

\section{(Equation 5)}

$$
M A E=\frac{1}{n} \sum_{i=1}\left|f_{i}-f_{j}\right|
$$

(Equation 6)

Where $f_{i}$ is the value of the derived empirical model, and $f_{j}$ is the GTPs value. 


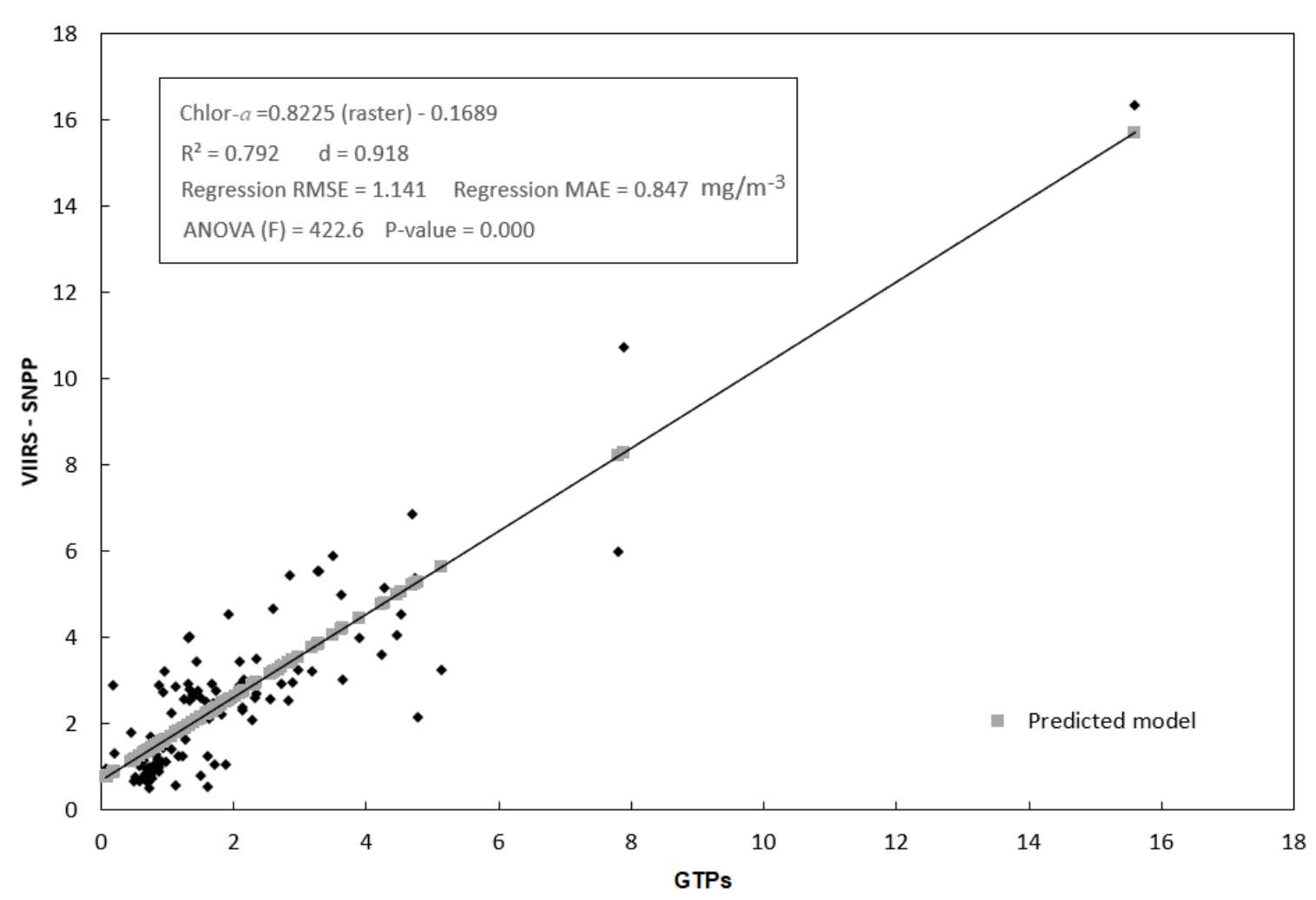

Fig. 2. The correlation between GTPs and satellite data of VIIRS - SNPP level 2 products was estimated positively through regression analysis.

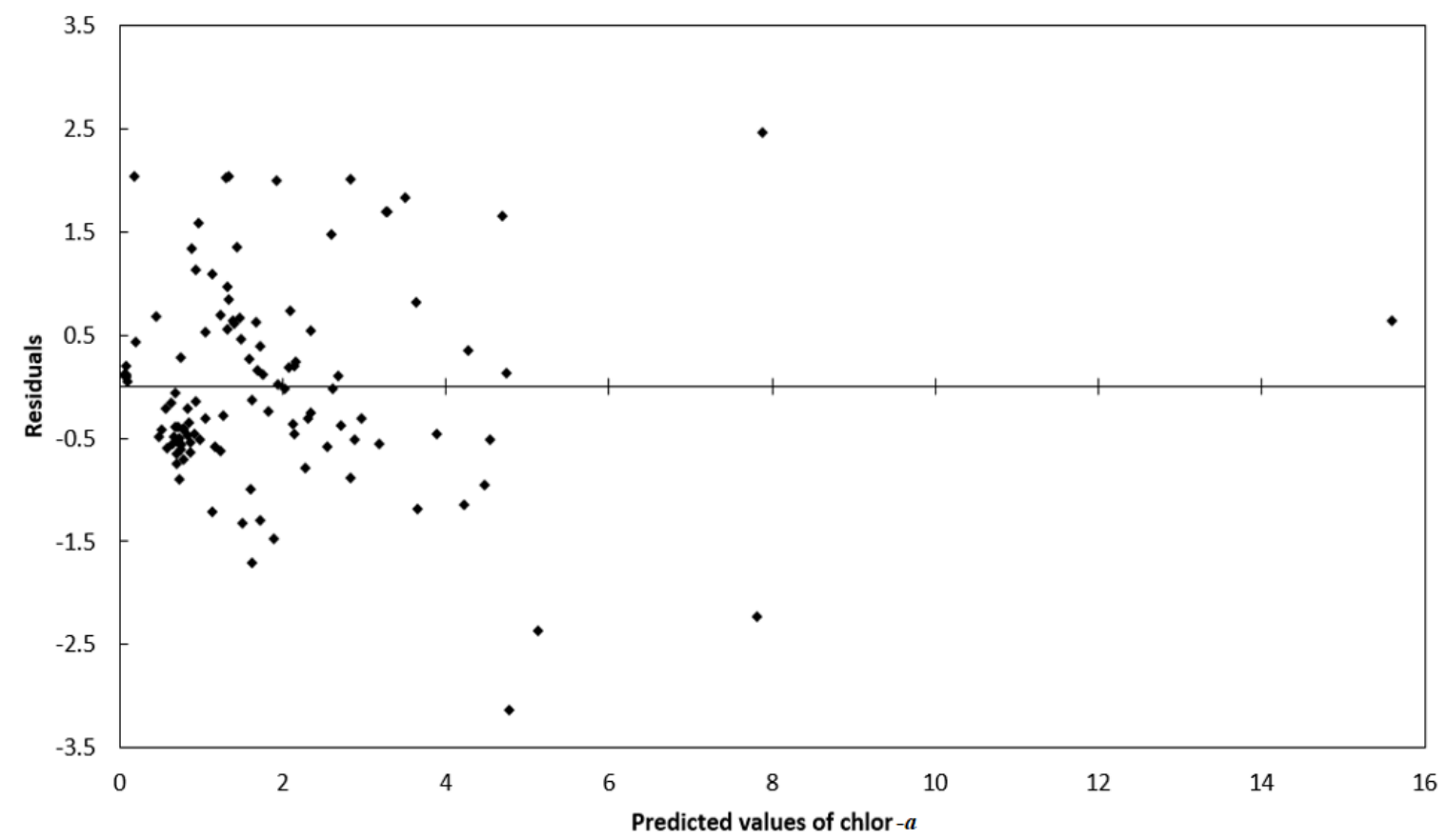

Fig. 3. The residual plot shows that the points are randomly dispersed around the horizontal axis, which confirmed that the linear regression model is appropriate for the data. 


\subsection{Raster analysis and spatial enchantment}

The level 3 chlor- $a$ concentration products of VIIRS - SNPP have been geometrically corrected to the WGS 84 coordinate reference system on BEAM - DIMAP format using SeaDAS 7.5.3 software. This format can be used in ArcGIS Pro software for more analysis. Following that, the regression algorithm has been applied to seasonal products. The data of the Arabian Gulf were directly analysed by extracting the spatial mean and standard deviation for each seasonal plate. The spatial mean is the average of all the pixels covered by the study area, where the standard deviation of the spatial mean describes how the chlor- $a$ concentration values deviate from the average. The seasonal mean values of the Arabian Gulf were used to show how the average changed over the study period. Moreover, the geophysical values of the north-west Arabian Gulf for each plate which covers Kuwait's territorial waters, have been clipped for analysing. The spatial resolution of the level 3 product data is 4 square $\mathrm{km}$ which means that these data are limited for mapping a large-scale area, such as Kuwaiti water (8000 square km). On the other hand, although the used data has acceptable spatial coverage, they falter in narrow areas, such as the creeks and embayments found on Kuwait's northern marine environment around Bubyan and Warba Islands, in addition to some parts of Kuwait Bay. To solve this issue, the values of each pixel on the North West Arabian Gulf have been extracted to build an inverse distance weighted (IDW) model. The IDW is a way to estimate an unknown point value from several surrounding known point values. The best results for this model are obtained when the distribution of control points (samples) is of high density and has a wide spatial spread over the study area concerned, in order to simulate all existing spatial differences; otherwise, the results of the model may be affected [52]. The IDW technique provides better accuracy in the spatial enhancement of raster model with conditions of high values of coefficient of variation, strong anisotropy and spatial structure [53]. These conditions were relatively identical to those in the model used. Additionally, Musashi et al. [54] showed more accuracy for this model than other derivative models. The IDW model was created based on 2000 extracted values from the north-western Arabian Gulf and has facilitated the increase of the spatial resolution to the maximum resolution, as determined by the function in ArcGIS Pro 2.3 toolbox (spatial analyst - interpolation tools) based on the number of points entered (Fig. 4). The following algorithm is used to calculate the inverse distance weighted (IDW) model:

$$
z x_{0}=\sum_{i=1}^{n} x_{i} / h_{i j}^{\beta}+\sum_{i=1}^{n} 1 / h_{i j}^{\beta}
$$

(Equation 7)

Where $z\left(x_{0}\right)$ is the output value, $x_{i}$ is the value of control known points, hij is the separation distance between the interpolated value and the control points value, and $\beta$ is the weighting power, $n$ is the total number of the control points (samples) values. 

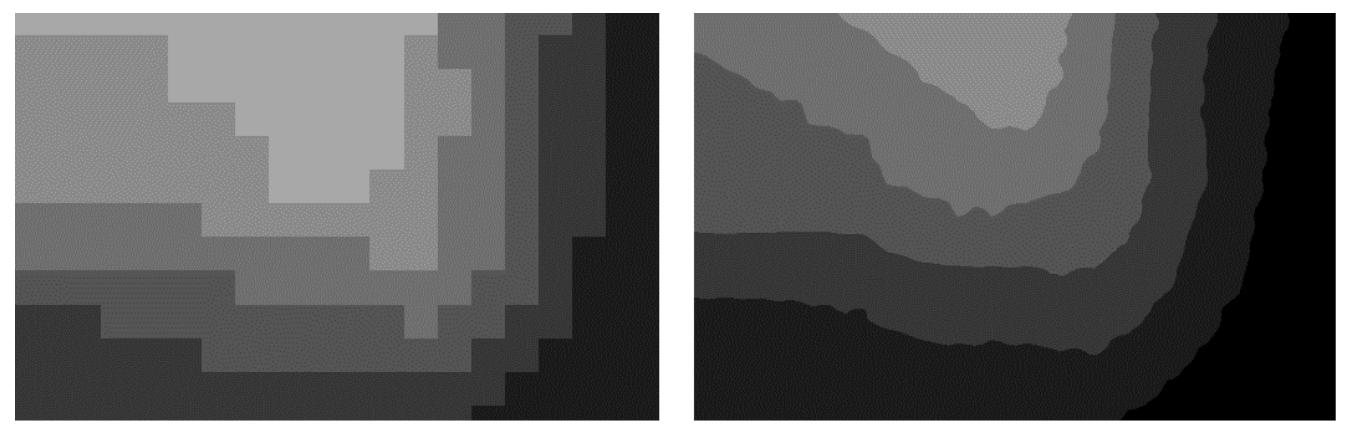

Fig. 4. Increasing the spatial resolution by applying the inverse distance weighted (IDW) model to the geophysical values of chlor- $a$ concentration products over the north-west Arabian Gulf.

Following that, the Kuwaiti water was divided into the north waters, Kuwait Bay, and the south waters (Fig. 5). This was based on the marine properties' similarities and differences that mentioned in the description of the study area. Mean and SD of each region were computed using zonal statistics. Additionally, Kuwait's territorial waters were classified into three areas based on their depth level in order to show the relationship of near-surface chlor- $a$ with the depth of Kuwaiti waters, the mean and SD for each class were calculated too.

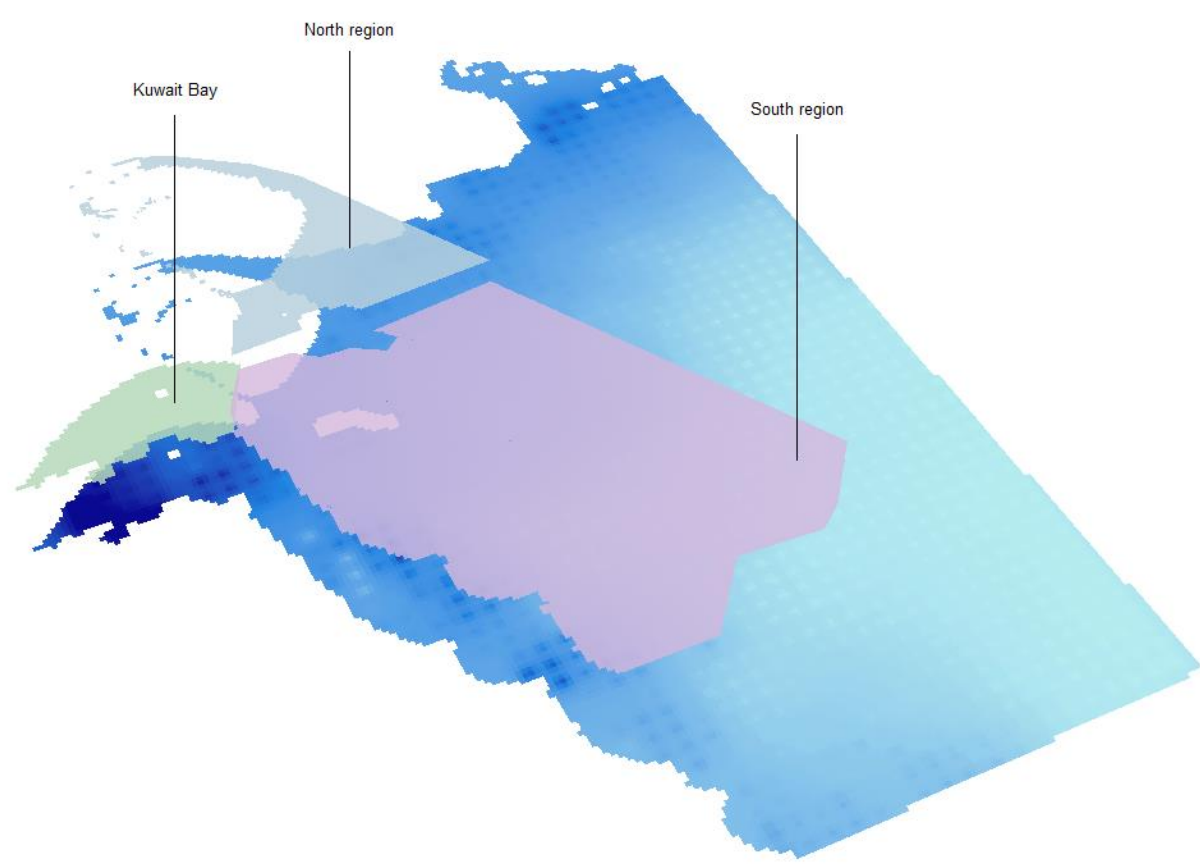

Fig. 5. The sub-regions of Kuwait water: the north region, Kuwait Bay and the south region.

Through 57 spatial mean GTPs, the IDW seasonal model was examined using the Mann Whitney test. The Mann Whitney test is a statistical hypothesis test used to compare two populations through their medians/means. This test can be used when the data do not follow a normal distribution, in addition to the other non-parametric testing conditions [55], which can be noticed by considering the histograms of chlor- $a$ concentrations. The following formulae were used to compute the Mann Whitney test: 


$$
U=\min \left(U_{1}, U_{2}\right)
$$

Where:

$$
\begin{aligned}
& U_{1}=n_{1} n_{2}+\frac{n_{1}\left(n_{1}+1\right)}{2}-R_{1} \\
& U_{2}=n_{1} n_{2}+\frac{n_{2}\left(n_{2}+1\right)}{2}-R_{2}
\end{aligned}
$$

(Equation 8)

Where $\eta_{1}$ and $\eta_{2}$ are the sample sizes, $\mathrm{R} 1$ and $\mathrm{R} 2$ are the sums of observations rank from sample 1 and 2 populations, respectively.

Fig. 6. shows the methodology summary, from downloading the data to the spatial analysis through the pre-processing and GTPs.

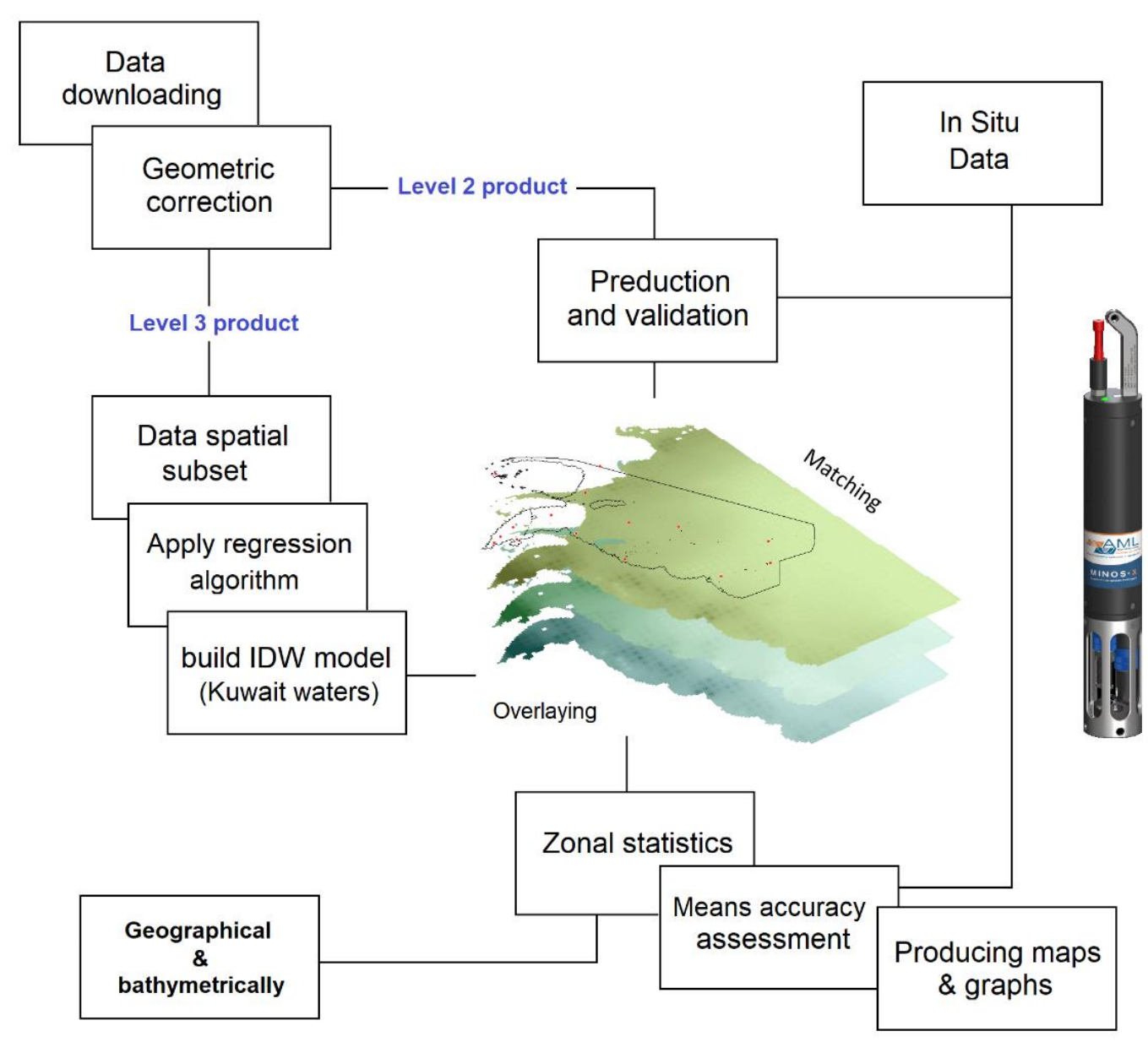

Fig. 6. Summary of the methodology. The data have been collected, pre-processed, analyzed and assessed through these steps. 


\section{Results and discussion}

\subsection{Accuracy assessment}

The validation results of the empirical level 2 chlor- $a$ concentration model derived from SNPP - VIIRS spectrometer using GTPs (number $=79$ ) monitored in the winter of 2017 and taken through 15 marine buoys showed a significant correlation. The statistical indices confirmed the strong correlation, where the overall RMSE and MAE were $= \pm 0.841$ and $0.638 \mathrm{mg} / \mathrm{m}^{-3}$ respectively. Thus, the empirical model has improved the accuracy by 0.329 and $0.256 \mathrm{mg} / \mathrm{m}^{-}$ ${ }^{3}$ where the RMSE and MAE were $= \pm 1.17$ and $0.841 \mathrm{mg} / \mathrm{m}^{-3}$ before applying the regression algorithm. Additionally, to give a greater perspective, the GTPs were separated into two different ranks according to their geographical location and the concentration level. Geographically, they were divided into two regions, with Kuwait Bay and the northern waters considered as one region; these showed an RMSE and MAE of \pm 1.11 and $0.89 \mathrm{mg} / \mathrm{m}^{-3}$. The northern waters were considered together with Kuwait Bay due to their relative lack of GTPs. By contrast, the southern region showed an RMSE and MAE of \pm 0.53 and $0.44 \mathrm{mg} / \mathrm{m}^{-3}$ (Fig. 7). The GTPs were also separated into two classes $(<2$ and $>2)$. The lower concentration values showed better accuracy $\left(\mathrm{RMSE}= \pm 0.552\right.$ and $\left.\mathrm{MAE}= \pm 0.468 \mathrm{mg} / \mathrm{m}^{-3}\right)$ than the higher $\left(\mathrm{RMSE}= \pm 1.09\right.$ and $\left.\mathrm{MAE}= \pm 0.84 \mathrm{mg} / \mathrm{m}^{-3}\right)$ (Fig. 8).

The regression algorithm has been applied to the derived IDW model from level 3 chlor- $a$ concentration data. The correlation between the seasonal averages of the IDW model and the seasonal averages of GTPs $(n=57)$ taken over 15 marine buoys in 2017 was tested by Mann Whitney test, where the null hypothesis rejected ( $\mathrm{sig}=0.948, \mathrm{p}<0.01-99 \%$ confidence). Overall, the empirical model decreases the average values of chlor- $a$ concentration over the study time and area, meaning that there is overestimation on the primary chlor- $a$ products of SNPP -VIIRS (Table. 1 and Fig. 9).
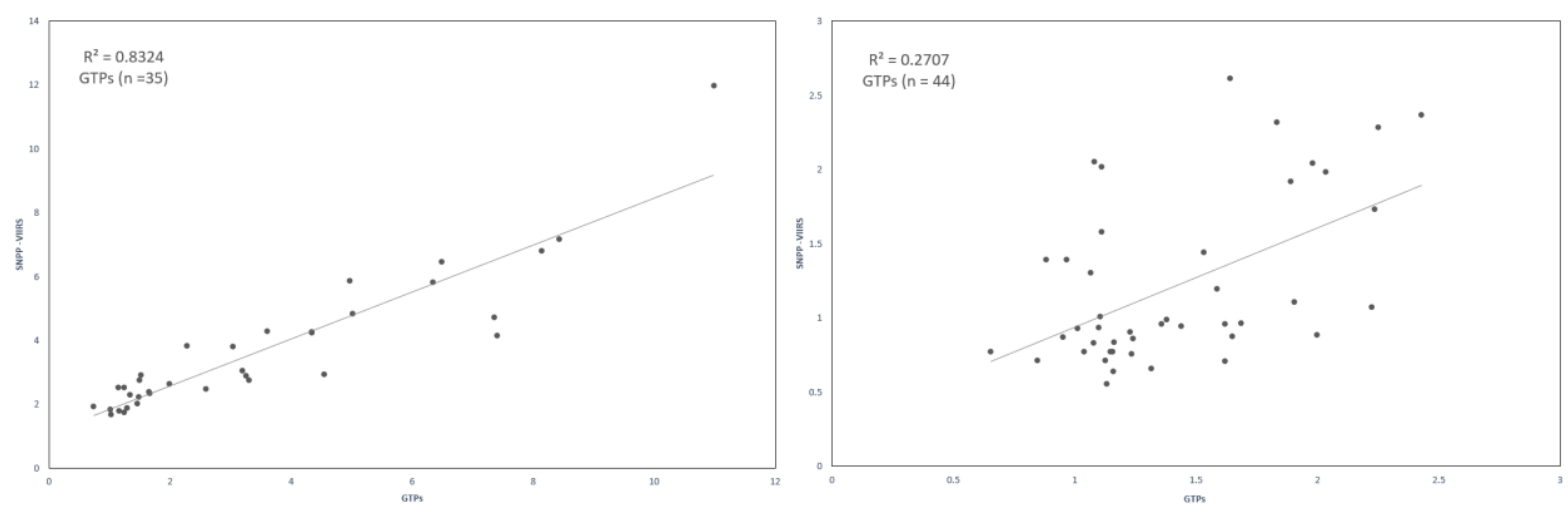

Fig. 7. The correlation between GTPs $(\mathrm{n}=35)$ and the empirical model in Kuwait Bay and northern waters $(\mathrm{a})$, and the correlation between GTPs $(\mathrm{n}=44)$ and the empirical model in southern waters (b). 

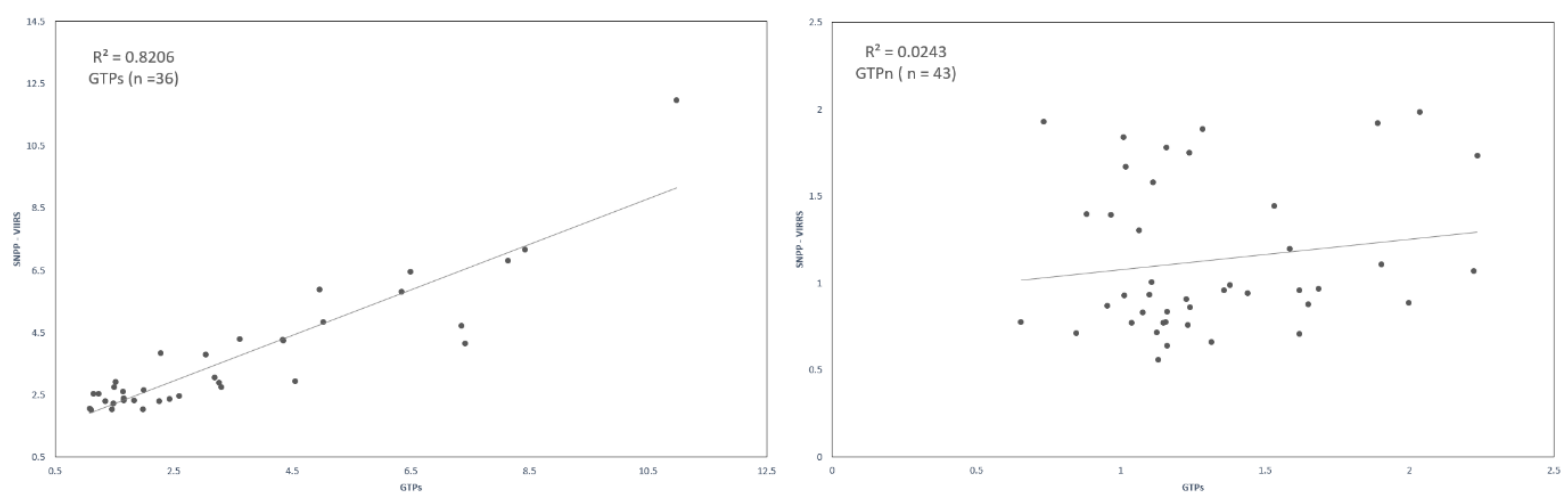

Fig. 8. The correlation between GTPs $(n=43)$ and the empirical model with fewer concentration values than $2 \mathrm{mg} / \mathrm{m}^{-3}(\mathrm{a})$, and the correlation between GTPs $(\mathrm{n}=36)$ and the empirical model with higher concentration values than $2 \mathrm{mg} / \mathrm{m}^{-3}$ (b).

Table 1 . The accuracy assessment by value, location and overall in Kuwait waters.

\begin{tabular}{cccccc}
\hline & \multicolumn{2}{c}{ By value } & \multicolumn{2}{c}{ By location } & Overall \\
\hline & $<2$ & $>2$ & Kuwait Bay \& North & South region & \\
\hline RMSE $( \pm)$ & 0.552 & 1.09 & 1.113 & 0.533 & 0.841 \\
MAE $( \pm)$ & 0.468 & 0.84 & 0.89 & 0.437 & 0.639 \\
\hline
\end{tabular}

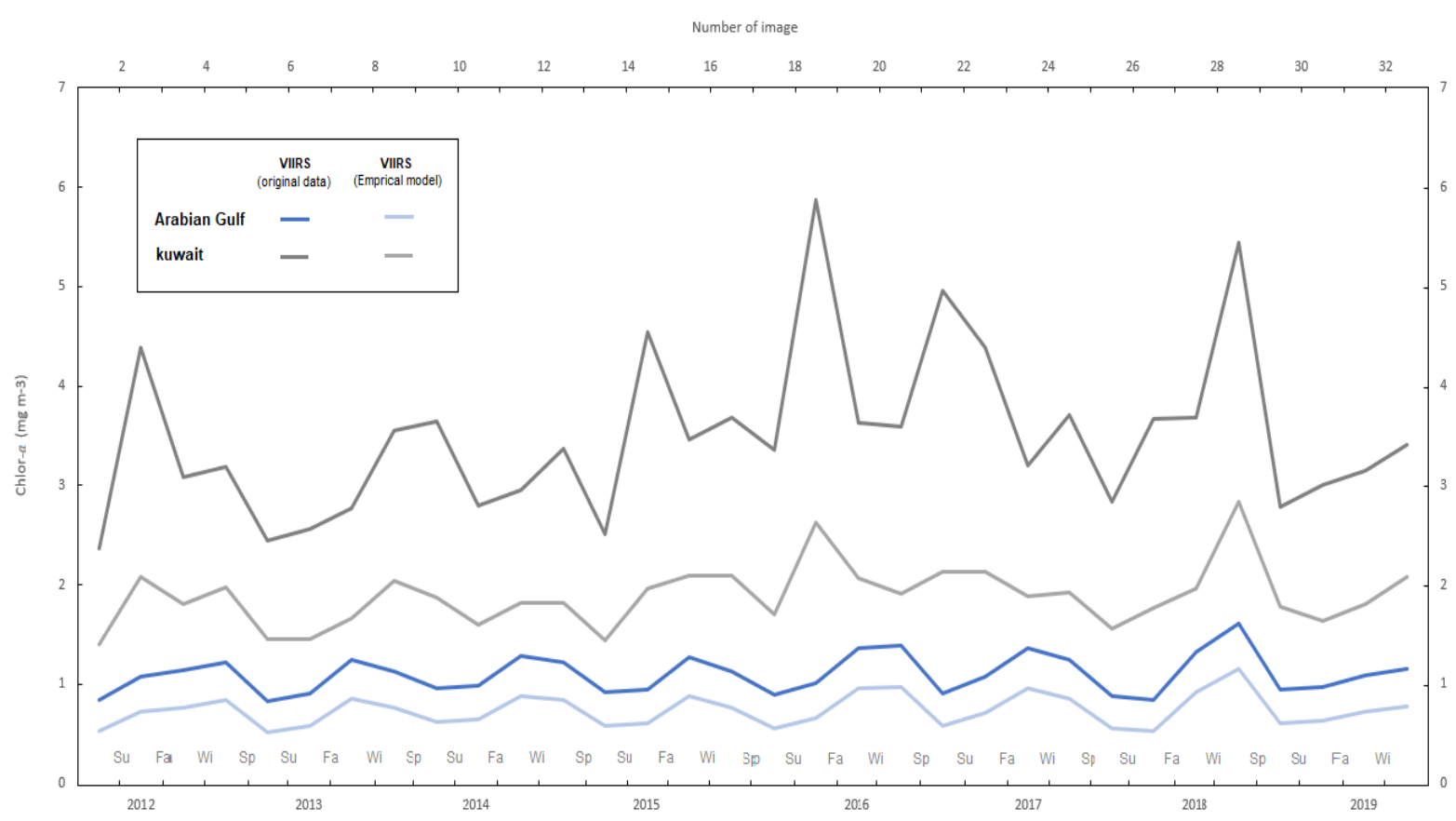

Fig. 9. The moving average of chlor- $a$ from 2012 to 2019 using the empirical model data of this study and VIIRS - SNPP original product data for both Kuwait and the Arabian Gulf. 
The validation results of the empirical model showed better accuracy to monitor lowconcentration waters, while the accuracy in high-concentration waters decreases. This pattern is inevitably affected by the degree of depth. Accordingly, the accuracy was measured geographically where the average depth is known. The results confirmed that the accuracy rises in deep water (southern waters of Kuwait) while it decreases in shallow and turbid water (Kuwait Bay and northern waters) (Table. 2). By reviewing the extracted chlor- $a$ concentration using different equations and the NASA satellite sensors for several seas and different bays around the world, with different numbers of GTPs (30-114), the accuracy varied in some literature from 0.18 to $0.64 \mathrm{mg} / \mathrm{m}^{-3}$ [32-35]. The accuracy was estimated at $0.23 \mathrm{mg} / \mathrm{m}^{-3}$ in the middle of the Arabian Gulf using 29 GTPs [2], and thus the accuracy of the empirical model developed in this study falls within a reasonable range, especially in a complex environment such as the north-west of the Arabian Gulf.

Despite the advantages of remote sensing data and solutions, this method does have some limitations. One of these limitations is that the accuracy of the obtained chlor- $a$ concentration results is affected by the depth and the high turbidity [23]; this is perhaps one of the most important characteristics of the Arabian Gulf, especially in the north-western region [28]. Therefore, developing a new and validated local model is essential [2]. However, the northern region of Kuwait waters is considered as one of the areas where chlor- $a$ models rarely monitor data according to the spatial resolution and coverage of the sensor, among other meteorological factors such as the dust bands [16], [17]. Accordingly, the developed spatial interpolation model for this region does have some limitations, especially with insufficient GTPs available to calibrate the results.

Table 2. The turbidity seasonal averages and standard deviation (NTU) obtained from KEPA buoys in 2017. The Kuwait Bay and the northern waters are characterized by higher turbidity than the southern waters over the year seasons.

\begin{tabular}{ccccc}
\hline & \multicolumn{2}{c}{ South region } & \multicolumn{2}{c}{$\begin{array}{c}\text { North region \& } \\
\text { Kuwait Bay }\end{array}$} \\
\hline & mean & SD & mean & SD \\
Spring & 4.14 & 7.39 & 5.45 & 7.19 \\
Summer & 2.65 & 7.37 & 6.23 & 7.25 \\
Fall & 5.57 & 7.37 & 6.46 & 7.32 \\
Winter & 2.69 & 7.33 & 6.13 & 7.32 \\
Overall & 3.76 & 7.36 & 6.07 & 7.27 \\
\hline
\end{tabular}




\subsection{Spatio-temporal variation}

Based on the sub-division of the Arabian Gulf [27, with mediations] (Fig. 1.), by knowing the water circulation and bathymetry of the Gulf [18], the analysis of seasonal averages from 2012 to 2019 via SNPP - VIIRS spectrometer shows that the coastal areas have higher chlor- $a$ concentrations compared to those in the open waters. Among the coasts, the Iranian eastern coast has a lower concentration than those in the west. However, the northern Shatt al-Arab coastal zone has the highest concentration of chlor- $a$ observed in winter and late fall, especially in its western parts, where the Kuwaiti waters are located (Fig. 10 and Fig. 11). In this area, Kuwait Bay has the highest concentration of chlor- $a$ as, in the southern waters, the deep-water characteristics begin to become clear. The northern waters also have a high chlor- $a$ concentration compared to the southern waters, (Fig. 12 and Fig. 13). The physical, topographical and anthropogenic factors contribute to the high level of chlor- $a$ in the northwestern zone: shallow depths contribute to the arrival of nutrients from the deep rich layers [41], the discharge of the rivers in the northern Arabian Gulf, the general water circulation in the Gulf that carries nutrients to the north-western coasts of the Arabian Gulf [18], and the human stresses on the coastal areas [39]. However, O'Reilly et al. [22] point out that an overestimation by remote sensing instruments can happen in this area due to the high turbidity (see Table. 2) and bottom reflection.

As for the seasonal change, chlor- $a$ in the Arabian Gulf between 2012 and 2019 is at its lowest concentration in spring, where the quarterly average reaches $0.57 \mathrm{mg} / \mathrm{m}^{-3}$. The concentration rises in summer as the average reaches $0.64 \mathrm{mg} / \mathrm{m}^{-3}$. The concentration continues to rise at the beginning of fall, where the average hits $0.87 \mathrm{mg} / \mathrm{m}^{-3}$, and this remains fairly steady in winter too. In this season, the high concentration is noticeable in the north-western region, and on the western coasts, as well as at the entrance to the Arabian Gulf in the Strait of Hormuz, where the concentration rises significantly until it reaches around $6 \mathrm{mg} / \mathrm{m}^{-3}$ (Table. 3). The subregions of Kuwait's waters follow a seasonal pattern comparable to the general seasonal cycle of the Arabian Gulf waters. The seasonal peak can be found between fall and winter, while the concentration reaches a low in the summer. However, the annual average concentration of chlor- $a$ in Kuwait Bay rises significantly, with a difference of $1.86 \mathrm{mg} / \mathrm{m}^{-3}$ over the southern region, and $0.57 \mathrm{mg} / \mathrm{m}^{-3}$ over the northern region. Fig. 14 shows the seasonal differences, while Table. 4 looks at both the averages and the standard deviation variation. The drop in chlor- $a$ concentration in fall is often due to depleted nutrients by the phytoplankton bloom in winter [2]. Nezlin et al. [21] clearly show that the seasonal cycle of chlor- $a$ concentration in tropical and subtropical oceans is typical. This is because the phytoplankton growth is affected by the low nutrients because of the strong pycnocline formation, in addition to the effects of thermal stratification in the water column, which limits the vertical mixing so that the nutrient rise to the surface [56]. This study result is consistent with other studies regarding seasonal changes $[2,13,21]$. 

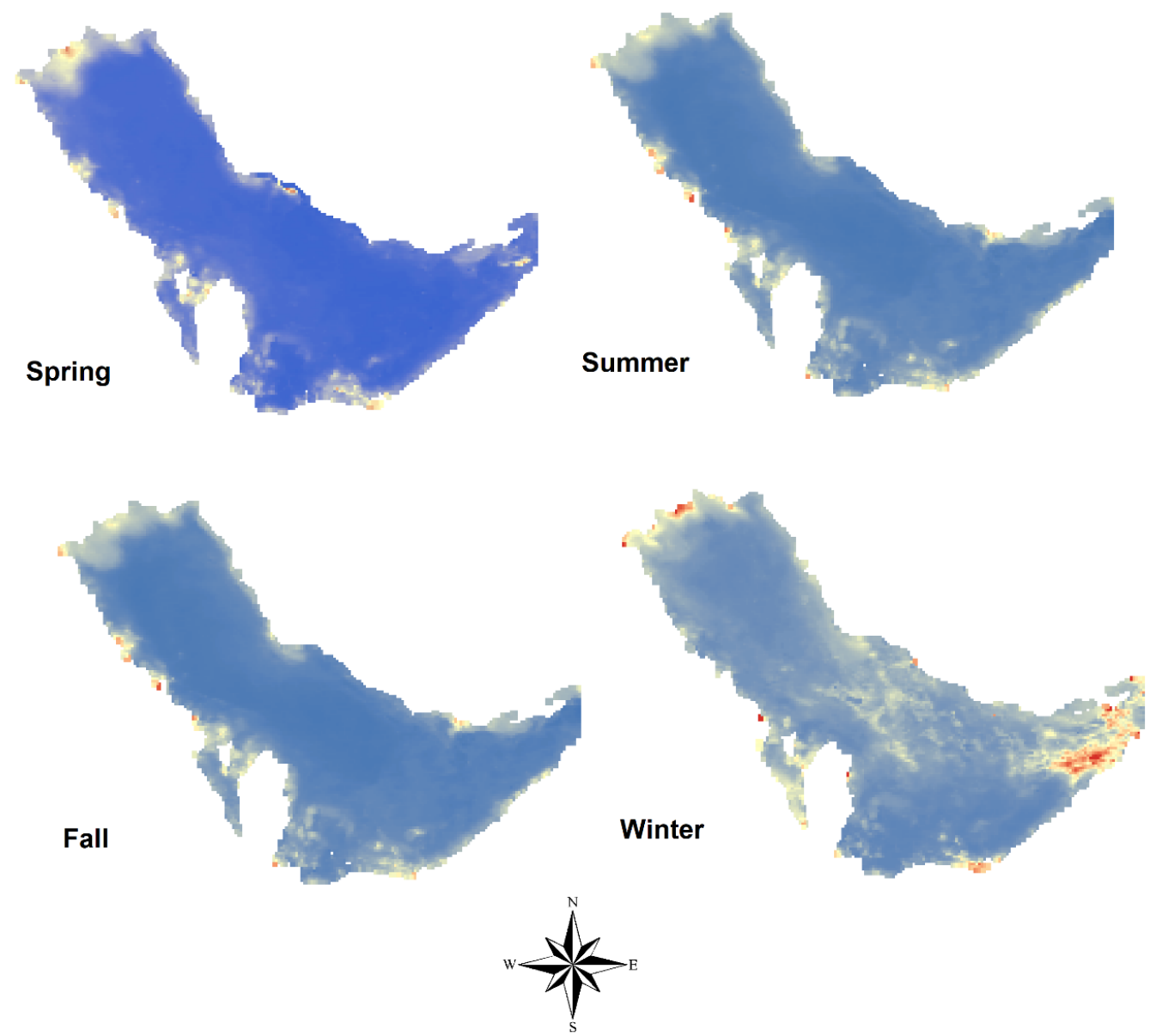

Chlor- $a\left(\mathrm{mg} \mathrm{m}^{-3}\right)$

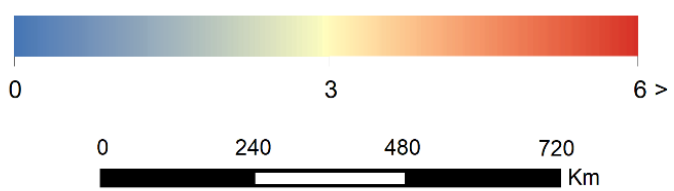

Fig. 10. The spatial distribution of chlor- $a$ concentration seasonal averages in the Arabian

Gulf from 2012 to 2019. The chlor- $a$ concentration increases in winter in the Strait of Hormuz and in the northern waters of the Arabian Gulf. 

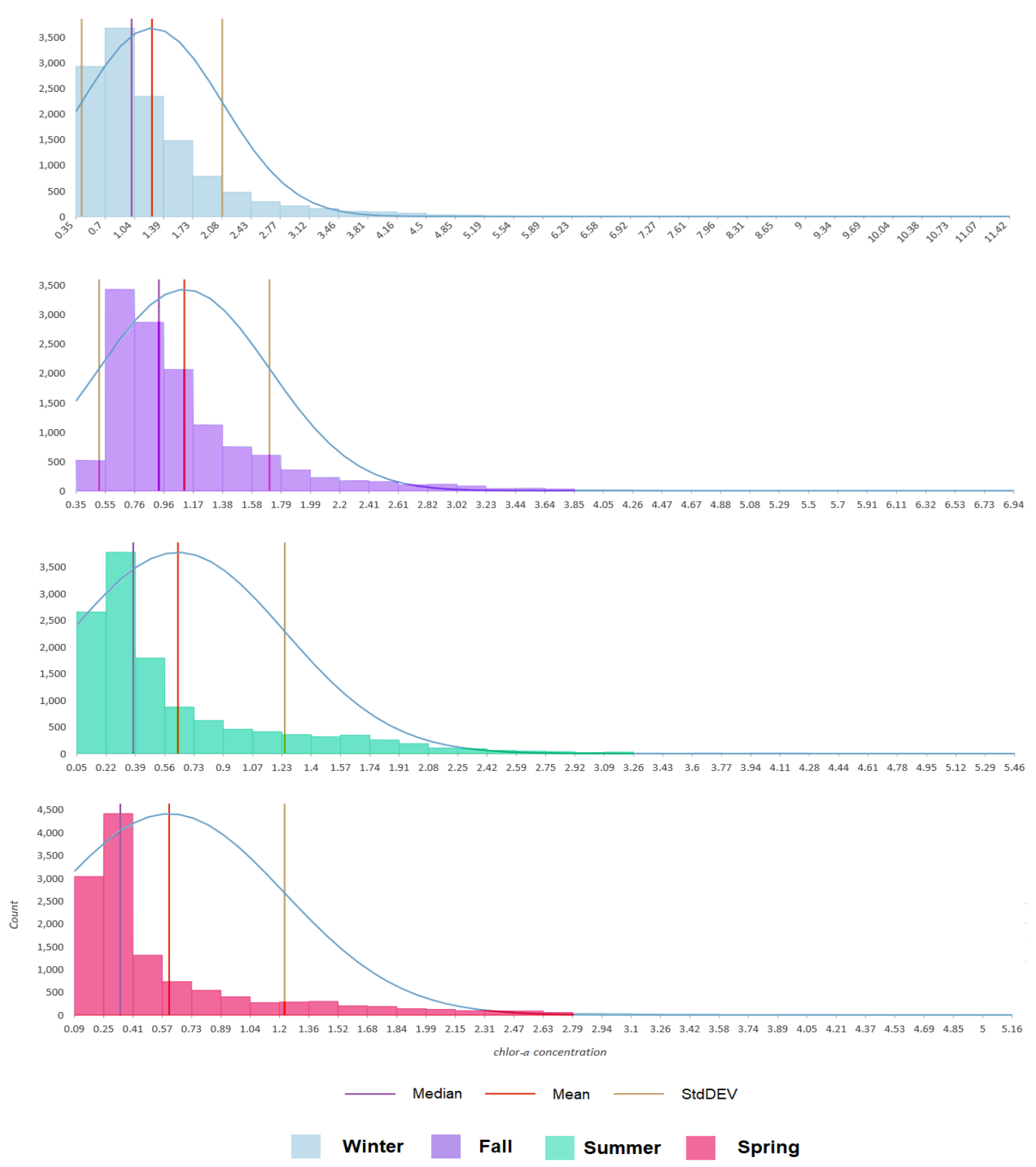

Fig. 11. The statistical distribution of chlor- $a$ concentration seasonal averages in the Arabian Gulf from 2012 to 2019. The chlor- $a$ concentration variation increases in summer and spring, while it is more gradual in winter and autumn. 

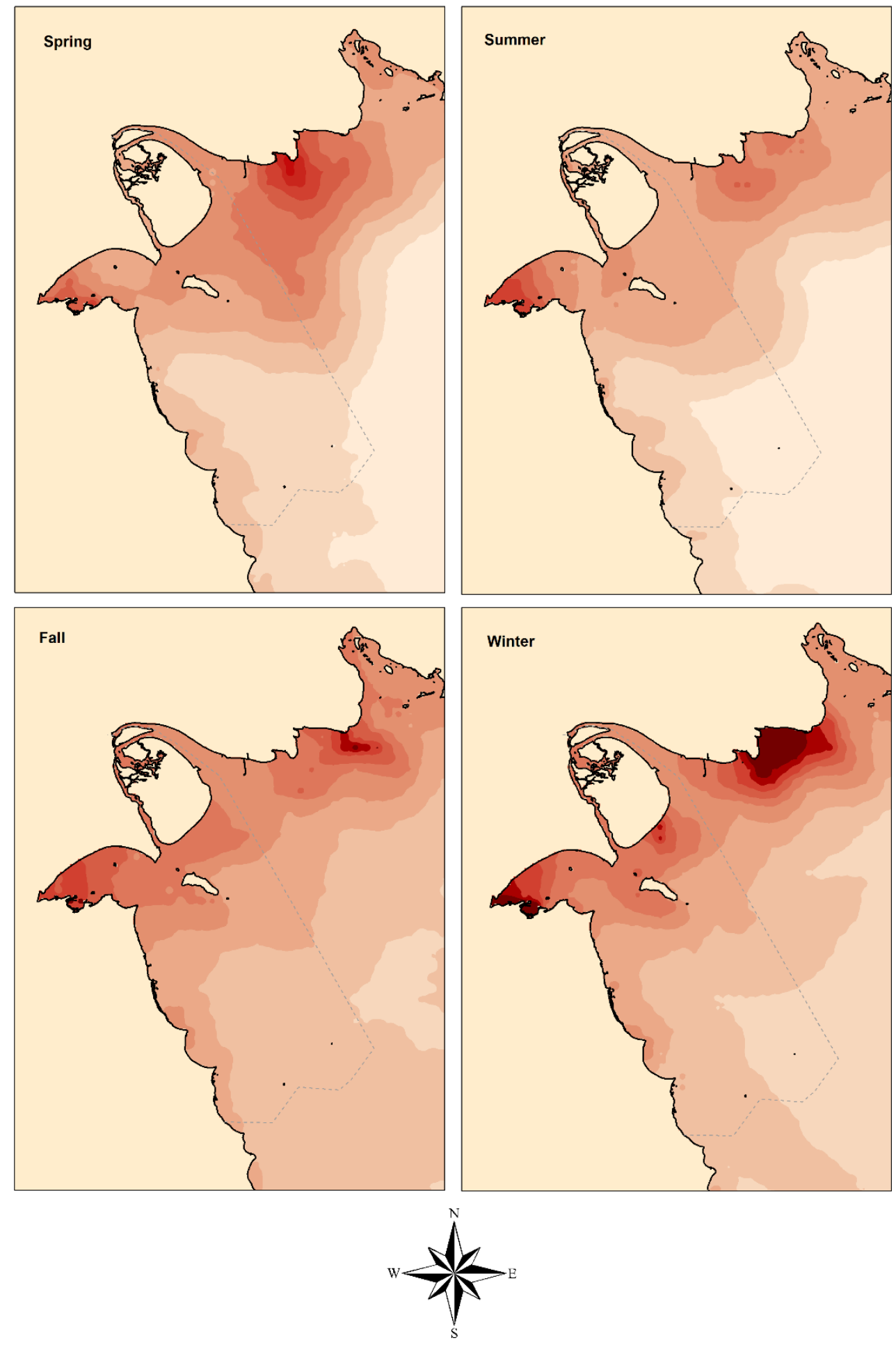

Chlor $-a\left(\mathrm{mg} \mathrm{m}^{-3}\right)$

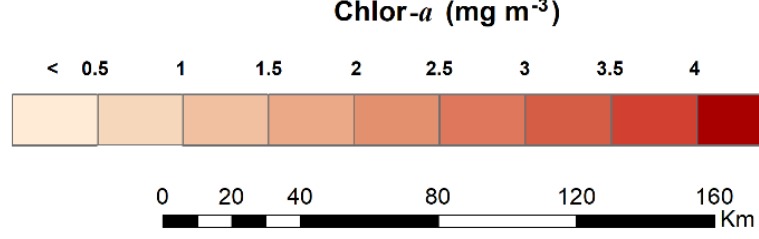

Fig. 12. The spatial distribution of chlor- $a$ concentration seasonal averages in Kuwait waters and the north-western Arabian Gulf from 2012 to 2019. The chlor- $a$ concentration increases in winter in Kuwait Bay and the northern waters of the Arabian Gulf. 

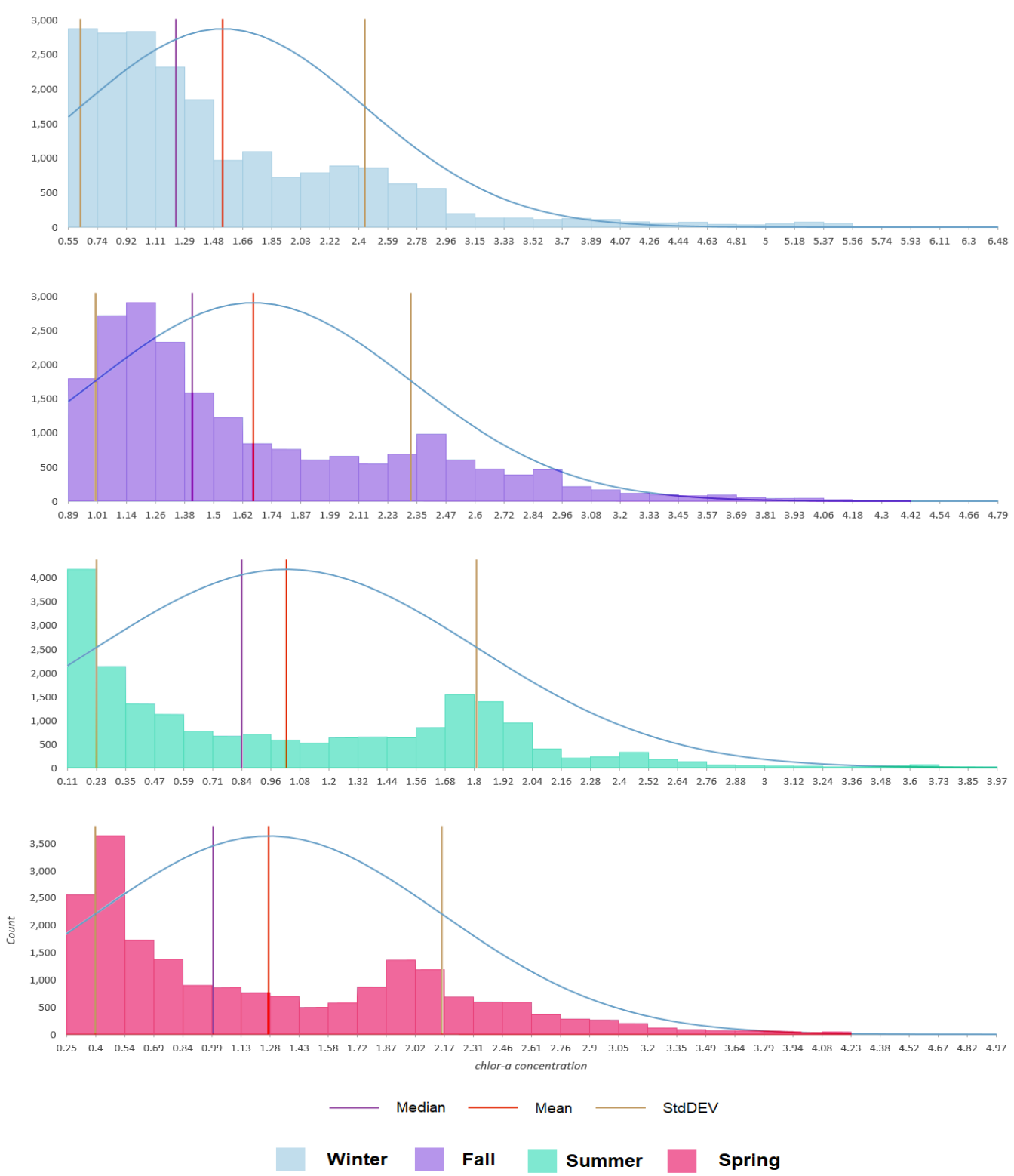

Fig. 13. The statistical distribution of chlor- $a$ concentration seasonal averages in Kuwaiti waters and the north-western Arabian Gulf from 2012 to 2019. The peak of the seasonal curves can be seen at low concentrations. A clear second smaller peak of chlor- $a$ concentration can be observed at $1.8-2 \mathrm{mg} / \mathrm{m}^{-3}$ in summer and spring.

Table 3. The seasonal means and standard deviations for both the Arabian Gulf and Kuwaiti territorial waters.

\begin{tabular}{ccccc}
\hline & \multicolumn{2}{c}{ Kuwait } & \multicolumn{2}{c}{ Arabian Gulf } \\
\hline & mean & SD & mean & SD \\
Spring & 1.88 & 0.38 & 0.57 & 0.38 \\
Summer & 1.81 & 0.43 & 0.64 & 0.5 \\
Fall & 2.41 & 0.35 & 0.87 & 0.47 \\
Winter & 2.38 & 0.56 & 0.87 & 0.48 \\
Overall & 2.12 & 0.43 & 0.74 & 0.46 \\
\hline
\end{tabular}


Table 4. The seasonal means and standard deviation for the sub-regions of Kuwaiti territorial waters from 2012 to 2019.

\begin{tabular}{lcccccc}
\hline & \multicolumn{2}{c}{ Kuwait Bay } & \multicolumn{2}{c}{ South region } & \multicolumn{2}{c}{ North region } \\
\hline & mean & SD & mean & SD & mean & SD \\
Spring & 2.3 & 0.48 & 1.11 & 0.48 & 2.22 & 0.18 \\
Summer & 2.64 & 0.65 & 0.93 & 0.52 & 1.86 & 0.12 \\
Fall & 3.21 & 0.38 & 1.55 & 0.37 & 2.47 & 0.31 \\
Winter & 3.21 & 0.78 & 1.39 & 0.45 & 2.54 & 0.44 \\
Overall & 2.84 & 0.57 & 1.24 & 0.46 & 2.27 & 0.26 \\
\hline
\end{tabular}

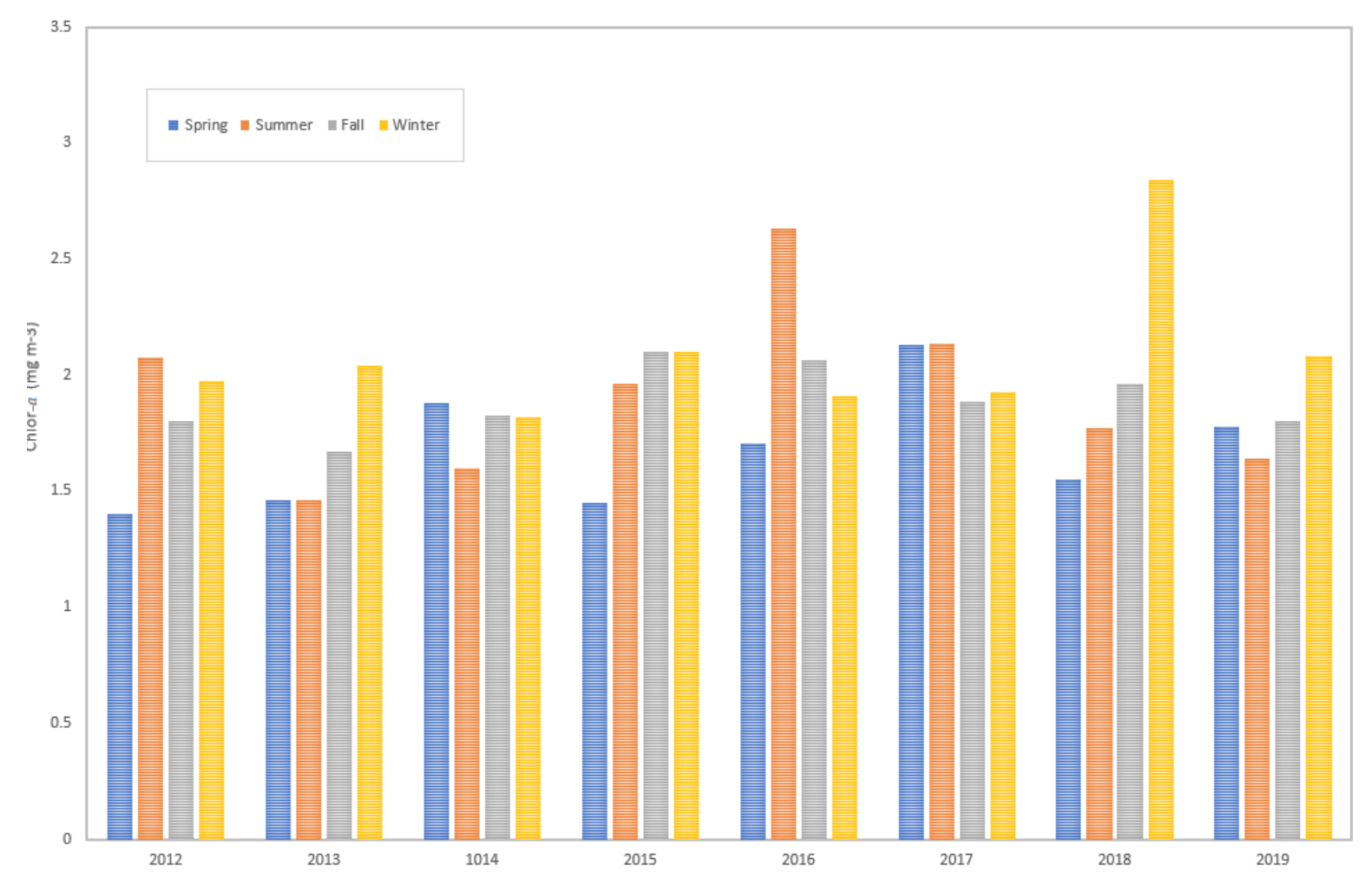

Fig. 14. The seasonal averages for Kuwait's territorial waters from 2012 to 2019. The seasonal pattern of chlor- $a$ concentration appears to be erratic in Kuwait's water.

The trend of chlor- $a$ concentration in the Arabian Gulf and Kuwait waters during the period from 2012 to 2019 shows that the average concentration fluctuates in semi-regular seasonal cycles that mostly rise around winter and late fall. However, the chlor- $a$ concentration average fluctuated between approximately 0.5 and $1 \mathrm{mg} / \mathrm{m}^{-3}$ during the study period, 2012 to 2019 . The highest average concentration was found in winter 2018 when it exceeded $1 \mathrm{mg} / \mathrm{m}^{-3}$ (Fig. 15). The chlor- $a$ concentration in Kuwait's waters shows that the seasonal cycles are less regular and more severe than those of the Gulf as a whole. Kuwaiti waters lie in the Shatt al-Arab region, which has a higher concentration overall, and a more complicated cycle affected by the complex river-sea system. However, the highest peak was observed between winter 2018 and fall 2019. The results indicate that the average chlor- $a$ concentration in Kuwait waters is increasing (Fig. 16). Fig. 17 shows the seasonal moving average of chlor- $a$ concentration in sub-regions of Kuwait's water from 2012 to 2019. 
Kuwait's waters take a quarterly concentration course similar to what is found in the Gulf as a whole. Taking into consideration the high average concentration in the north-western region of the Arabian Gulf, especially in Kuwait Bay, where the values are significantly higher than the northern and southern regions. This is consistent with Al-Yamani et al.'s study [28] of spatial changes in Kuwait's chlor- $a$ concentration. Additionally, the long-term results showed regular seasonal changes at the Arabian Gulf level with peaks in certain years, while it was less regular in Kuwait's waters, where remarkable leaps were seen, especially those in Kuwait Bay.

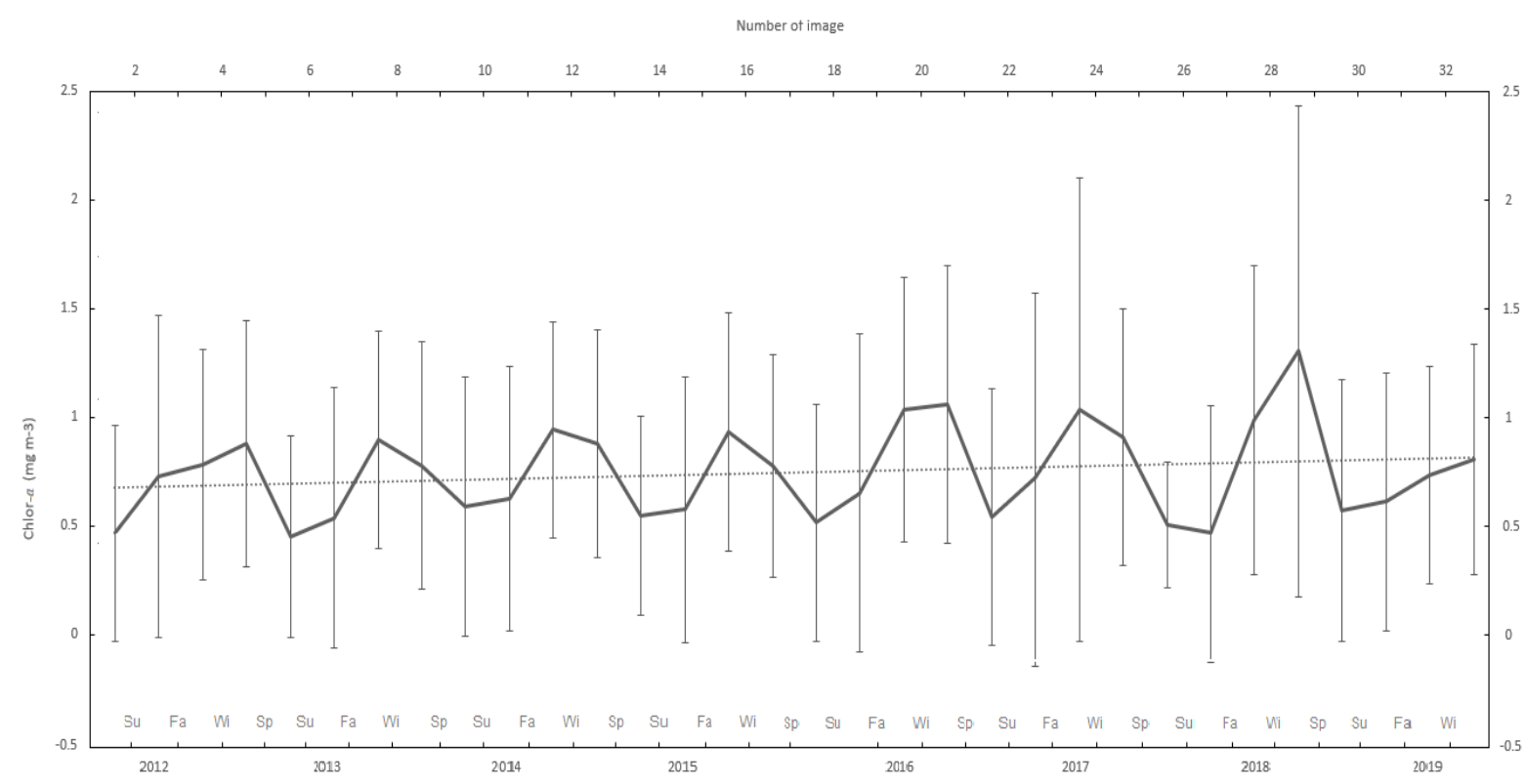

Fig. 15. The seasonal moving average trend and pattern of chlor- $a$ concentration in the Arabian Gulf from 2012 to 2019. a semi-regular cycle during the years of study can be observed.

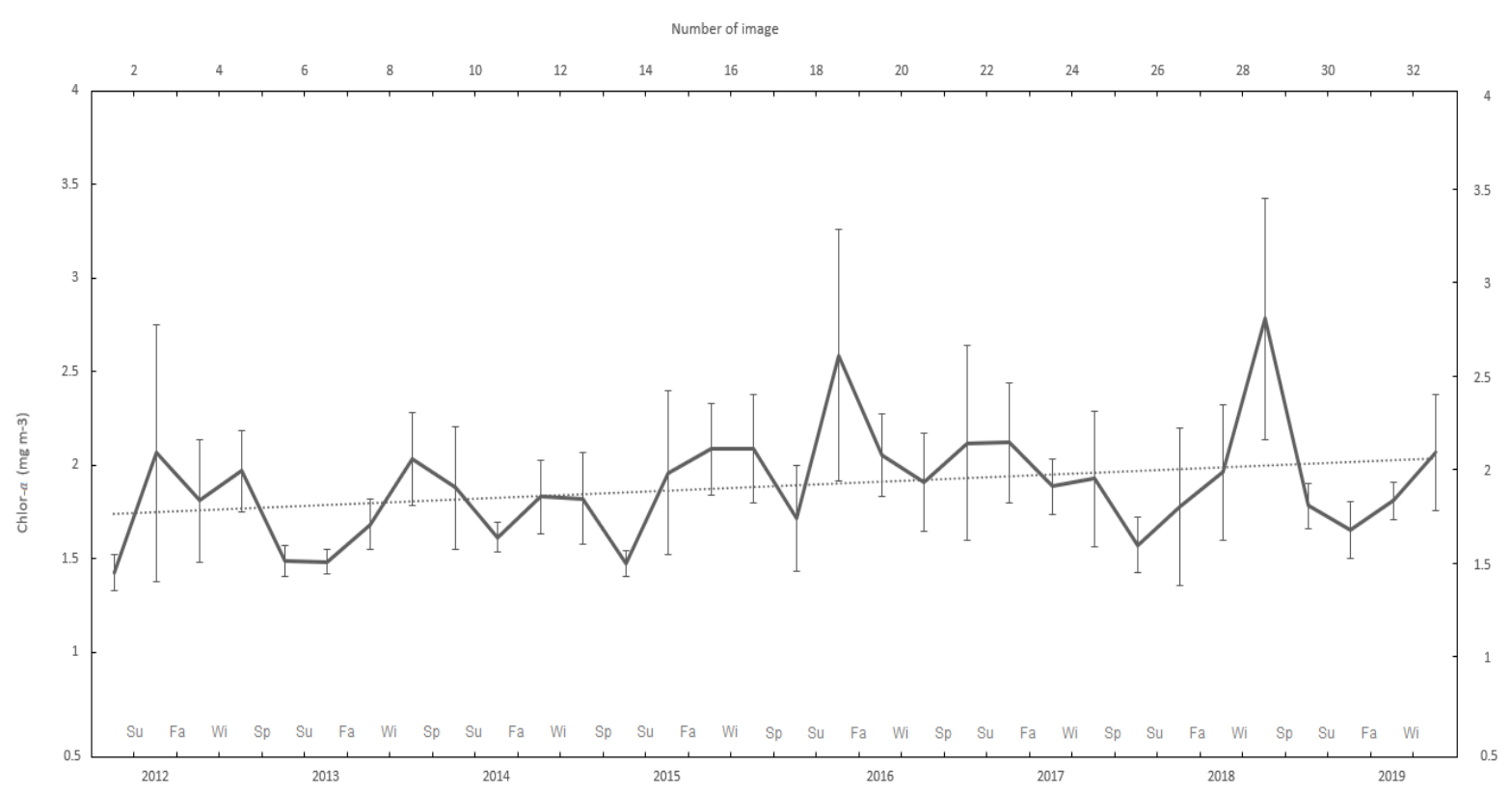

Fig. 16. The seasonal moving average of chlor- $a$ concentration in Kuwait's territorial waters from 2012 to 2019. Two peaks can be seen in 2016 and 2018. 


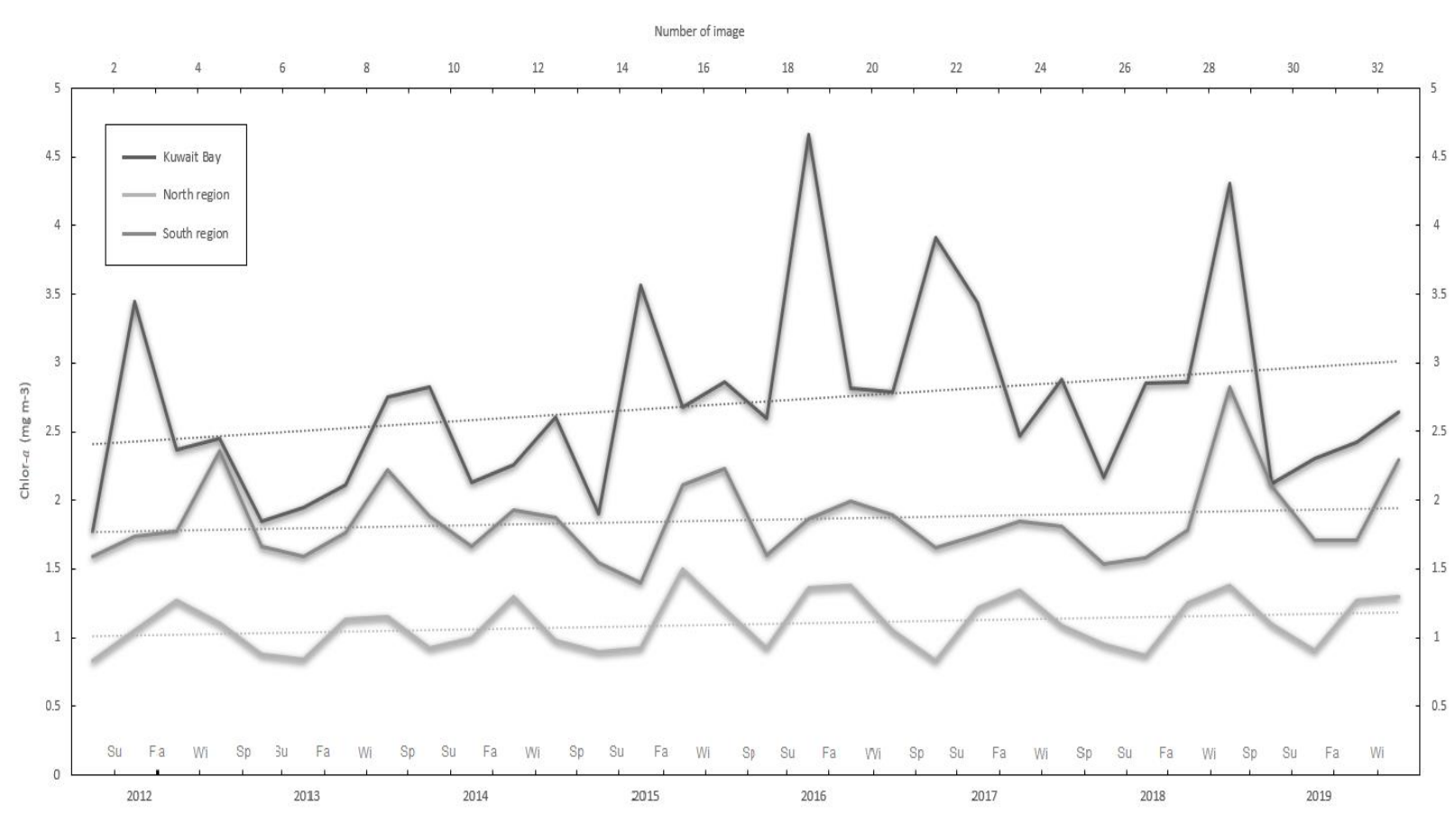

Fig. 17. The seasonal moving average of chlor- $a$ concentration in sub-regions of Kuwait's water from 2012 to 2019. The pattern in Kuwait Bay is more extreme than in the northern and southern waters.

\subsection{Chlor- $a$ vs bathymetry}

The spatial distribution of chlor- $a$ concentration derived from the empirical model of SNPP VIIRS level 3 data was studied over three bathymetric classes extracted and analysed by the spatial interpolation model derived from the depth GTPs taken over Kuwait's waters. The results confirmed that the chlor- $a$ concentration is affected by the level of depth, where the means decrease proportionally with higher depths. At shallower depths (less than 10 meters), the average chlor- $a$ concentration over a period of eight years (2012 to 2019) comes out at 2.34 $\mathrm{mg} / \mathrm{m}^{-3}$. However, the concentration decreases gradually to $1.5 \mathrm{mg} / \mathrm{m}^{-3}$ in the depth range of 10 to 20 meters, and continues to drop until it reaches $0.88 \mathrm{mg} / \mathrm{m}^{-3}$ at 20 meters and greater. The chlor- $a$ concentration level decreases steadily when depth increases at 10 -meter intervals. The standard deviation decreases by about 0.2 with an increase of every ten meters in depth. This correlation applies to all seasons, with similar degrees of decline with rising depth (Table. 5).

Although many studies have indicated that the concentration of nutrients increases to a depth of 1000 meters in different seas of the world [57, 58], and the mixing process can raise the nutrients from the rich near-bottom to the near-surface layer [59]; the limited upwelling process in the Arabian Gulf causes limited nutrient concentration in the offshore and the northern open water of the Arabian Gulf [38]. This may explain the lower chlor- $a$ concentration in the southern water of Kuwait. In contrast, many sources feed the submerged northern estuarine flat where Kuwait Bay can be found. The standard deviation of the chlor- $a$ concentration raises slowly with decreasing depth; this explains that the chlor- $a$ concentration is more homogenous in deep areas, such the southern water of Kuwait, than in the shallow areas such as Kuwait Bay, which is a shallow semi-closed water, with the river freshwater discharge bringing the nutrients from the land. Further anthropogenic stresses and the presence of sewage pouring into the water of the Bay [39] may be other reasons for the increase in the concentration of chlorophyll and its relatively wide spatial variation. Fig. 18 shows a 3D bathymetric model of near-surface 
chlor- $a$ concentration, which clearly shows the spatial relationship between depth and chlor- $a$ concentration over the north-western Arabian Gulf (Kuwait's waters). The submerged northern estuarine flat has a higher average seasonal concentration compared to the other parts of Kuwaiti water.
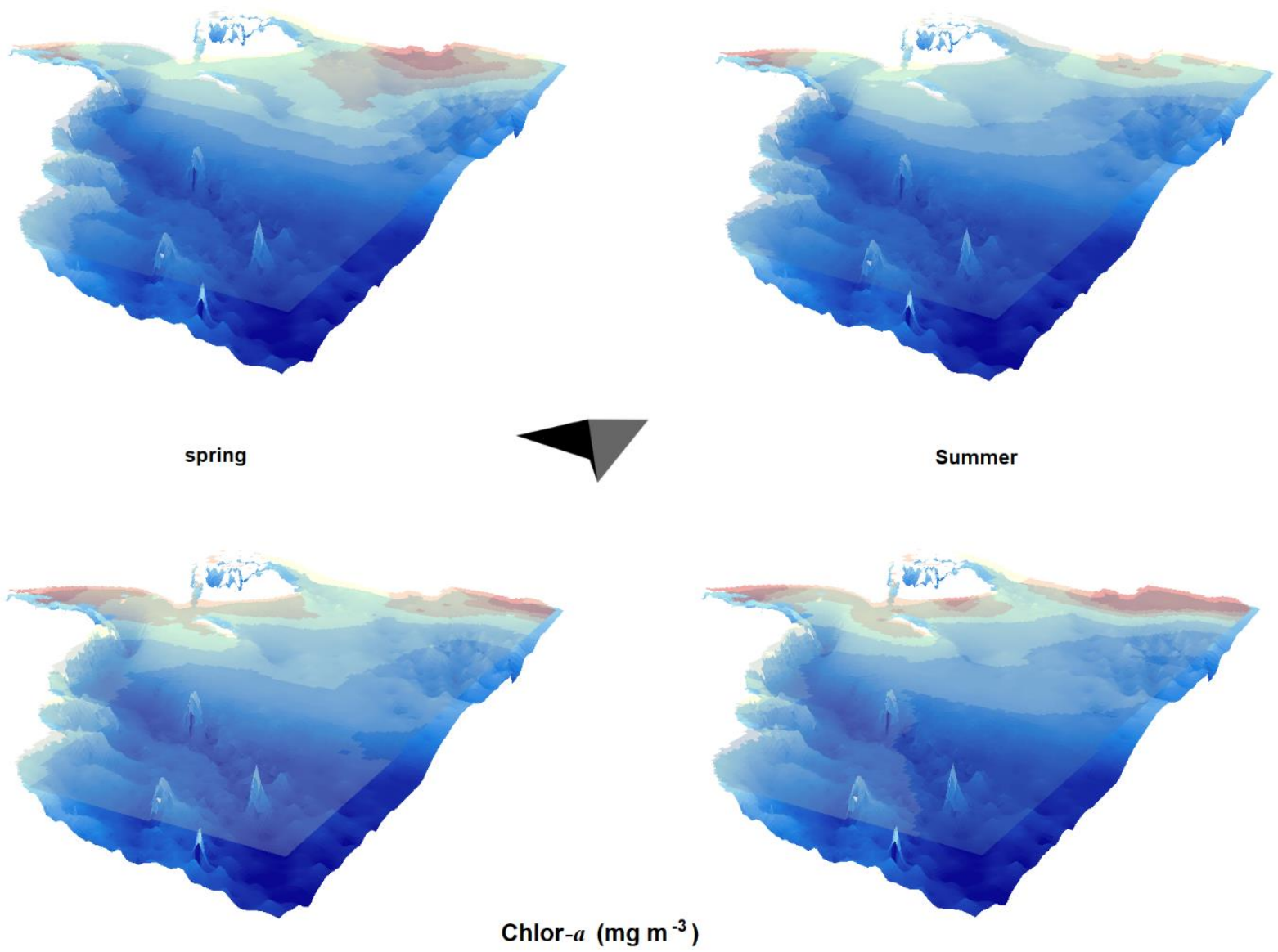

Chlor-a $\left(\mathrm{mg} \mathrm{m}^{-3}\right)$

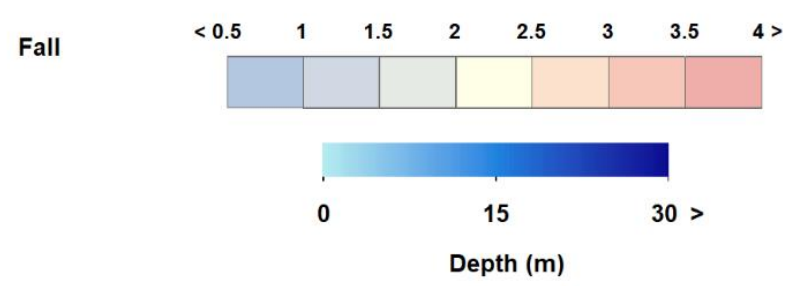

Winter

Fig. 18. 3D models show the seasonal averages of chlor- $a$ concentration from 2012 to 2019 over the north-eastern Arabian Gulf bathymetry (Kuwaiti waters). It can be noted that the concentration increases as the depth decreases (the northern area, for example). 
Table. 5. The seasonal chlor- $a$ concentration decreases as the water depth increases. Three ranges of depth show the concentration values level of change by averages and standard deviation (data 2012 - 2019).

\begin{tabular}{|c|c|c|c|c|c|c|}
\hline & \multicolumn{2}{|c|}{$<10$} & \multicolumn{2}{|c|}{10 to 20} & \multicolumn{2}{|c|}{$>20$} \\
\hline & mean & SD & mean & SD & mean & SD \\
\hline Spring & 2.32 & 0.65 & 1.61 & 0.66 & 0.7 & 0.25 \\
\hline Summer & 1.97 & 0.52 & 1.2 & 0.5 & 0.46 & 0.3 \\
\hline Fall & 2.44 & 0.59 & 1.65 & 0.41 & 1.29 & 0.24 \\
\hline Winter & 2.64 & 0.98 & 1.53 & 0.43 & 1.05 & 0.27 \\
\hline Overall & 2.34 & 0.69 & 1.5 & 0.5 & 0.88 & 0.27 \\
\hline
\end{tabular}

\section{Conclusion}

In this study, the seasonal spatial and temporal distribution of near-surface chlor- $a$ concentration in the Arabian Gulf and Kuwait waters from 2012 to 2019 was studied and explained using SNPP - VIIRS spectrometer data. The study included the use of a new empirical model based on GTPs observed in 2017 and taken from the Arabian Gulf specifically in the north-west, where Kuwait waters are located. Additionally, the relationship between chlor- $a$ concentration and the depth of Kuwaiti waters has been studied, where the spatial resolution of the model was improved to clearly show the spatial dimension in this specific area The results showed that the chlor- $a$ concentration rises near the coasts and in the northwestern region of the Arabian Gulf (Kuwait waters), where this area was enhanced spatially. The results also showed that the chlor- $a$ concentration increases in Kuwait Bay while decreasing gradually towards the south. Seasonally, the chlor- $a$ concentration has a cycle that peaks in winter and early fall for both Kuwait waters and the wider Arabian Gulf. However, the trend of concentrations averages is more stable in the Arabian Gulf compared to Kuwait waters during the period of study. Additionally, the chlor- $a$ concentration was observed to be decreased at a stable level, as the depth increases. The accuracy of the empirical model was tested through GTPs and showed an overall RMSE and MAE of 0.841 and $0.638 \mathrm{mg} / \mathrm{m}^{-3}$, respectively. Remote sensing techniques provide valuable ways to understand the marine environment, including chlor- $a$ concentration and phytoplankton density in seas and oceans through the spatial modelling.

\section{Acknowledgements}

The author would like to thank the KEPA staff in the marine montoring section for collecting and analyzing the buoys data over 2017. Acknowledgement must also go to NASA (OceanColor) for the various geophysical products that have been provided for free. I would also extend my thanks to Mr. Ilyes Allani and Mr. Wahid Moufaddal from ROPME for the wide-ranging discussions about remote sensing of Kuwait's marine environment. 


\section{References}

[1] F. E. Muller-Karger, C. Hu, S. Andréfouët, R. Varela, and R. Thunell, "The Color of the Coastal Ocean and Applications in the Solution of Research and Management Problems," in Remote Sensing of Coastal Aquatic Environments: Technologies, Techniques and Applications, R. L. Miller, C. E. Del Castillo, and B. A. Mckee, Eds. Dordrecht: Springer Netherlands, 2005, pp. 101-127, doi: 10.1007/978-1-4020-31007_5.

[2] N. Al-Naimi, D. E. Raitsos, R. Ben-Hamadou, and Y. Soliman, "Evaluation of Satellite Retrievals of Chlorophyll- $a$ in the Arabian Gulf," vol. 301, no. 10, pp. 1-13, 2017, doi: $10.3390 /$ rs9030301.

[3] T. B. Al-Rashidi, H. I. El-Gamily, C. L. Amos, and K. A. Rakha, "Sea surface temperature trends in Kuwait Bay, Arabian Gulf," Nat. Hazards, vol. 50, no. 1, pp. 7382, 2009, doi: 10.1007/s11069-008-9320-9.

[4] A. B. Cahyono, H. D. Armono, and D. Saptarini, "Estimation of Sea Surface Temperature ( SST ) Using Split Window Methods for Monitoring Industrial Activity in Coastal Area," Trans Tech Publ. Switz. Submitt., vol. 862, no. January, pp. 90-95, 2017, doi: 10.4028/www.scientific.net/AMM.862.90.

[5] C. T. Mutlow, A. M. Zavody, I. J. Barton, and D. T. Llewellyn-Jones, "Sea surface temperature measurements by the along-track scanning radiometer on the ERS 1 satellite: early results," J. Geophys. Res., vol. 99, no. Cll, p. 22,522-575,588, 1994.

[6] A. Thomas, D. Byrne, and R. Weatherbee, "Coastal sea surface temperature variability from Landsat infrared data,” Remote Sens. Environ., vol. 81, no. 2-3, pp. 262-272, 2002, doi: 10.1016/S0034-4257(02)00004-4.

[7] S. Huang, J. Lin, Y. Lo, N. Kuo, and C. Ho, "The coastal sea surface temperature changes near the nuclear power plants of northern Taiwan observed from satellite images," Ocean. 2014, pp. 2-6, 2014.

[8] J. R. Jensen, Introductory Digital Image Processing “A Remote Sensing Perspective," 4th ed. Prentice Hall Press, 2016.

[9] G. N. Williams, A. I. Dogliotti, P. Zaidman et al., “Assessment of remotely-sensed seasurface temperature and chlorophyll- $a$ concentration in San Matías Gulf (Patagonia, Argentina)," Cont. Shelf Res., vol. 52, pp. 159-171, 2013, doi: https://doi.org/10.1016/j.csr.2012.08.014.

[10] J. A. Yoder, J. E. O’Reilly, A. H. Barnard, T. S. Moore, and C. M. Ruhsam, "Variability in coastal zone color scanner (CZCS) Chlorophyll imagery of ocean margin waters off the US East Coast," Cont. Shelf Res., vol. 21, no. 11, pp. 1191-1218, 2001, doi: https://doi.org/10.1016/S0278-4343(01)00009-7.

[11] A. P. Mendonça, A. M. Martins Martins, M. P. Figueiredo et al., "Evaluation of ocean color and sea surface temperature sensors algorithms using in situ data: a case study of temporal and spatial variability on two northeast Atlantic seamounts," J. Appl. Remote Sens., vol. 4, no. 1, pp. 1-26, 2010, doi: 10.1117/1.3328872.

[12] Y. Zhang, H. Jiang, C. Chen, X. Y. Zhang, and Y. Wang, "Wavelet analysis on chlorophyll concentration change in the area around Bohai Bay area, Yangtze River Delta Region and South China Sea," Procedia Environ. Sci., vol. 13, pp. 1373-1382, 
2012, doi: https://doi.org/10.1016/j.proenv.2012.01.130.

[13] M. Moradi and K. Kabiri, "Spatio-temporal variability of SST and Chlorophyll- $a$ from MODIS data in the Persian Gulf," Mar. Pollut. Bull., vol. 98, no. 1-2, pp. 14-25, 2015, doi: 10.1016/j.marpolbul.2015.07.018.

[14] M. Moradi and K. Kabiri, "Red tide detection in the Strait of Hormuz (east of the Persian Gulf) using MODIS fluorescence data," Int. J. Remote Sens., vol. 33, no. 4, pp. 10151028, 2012, doi: 10.1080/01431161.2010.545449.

[15] P. M. Glibert, J. H. Landsberg, J. J. Evans et al., "A fish kill of massive proportion in Kuwait Bay, Arabian Gulf, 2001: the roles of bacterial disease, harmful algae, and eutrophication," Harmful Algae, vol. 1, no. 2, pp. 215-231, 2002, doi: https://doi.org/10.1016/S1568-9883(02)00013-6.

[16] J. Zhao and H. Ghedira, "Monitoring red tide with satellite imagery and numerical models: A case study in the Arabian Gulf," Mar. Pollut. Bull., vol. 79, no. 1, pp. 305313, 2014, doi: https://doi.org/10.1016/j.marpolbul.2013.10.057.

[17] N. P. Nezlin, I. G. Polikarpov, F. Y. Al-Yamani, D. V Subba Rao, and A. M. Ignatov, "Satellite monitoring of climatic factors regulating phytoplankton variability in the Arabian (Persian) Gulf," J. Mar. Syst., vol. 82, no. 1, pp. 47-60, 2010, doi: https://doi.org/10.1016/j.jmarsys.2010.03.003.

[18] R. M. Reynolds, "Physical oceanography of the Gulf, Strait of Hormuz, and the Gulf of Oman-Results from the Mt Mitchell expedition," Mar. Pollut. Bull., vol. 27, no. August, pp. 35-59, 1993, [Online]. Available: https://scholar.google.com/scholar?hl=en\&as_sdt=0\%2C5\&q=Physical+oceanography +of+the+Gulf $\% 2 \mathrm{C}+$ Strait+of + Hormuz $\% 2 \mathrm{C}+$ and +the+Gulf +of+Oman+results+from+the+Mt.+Mitchell+expedition.+Mar+Pollut+Bull+27\%3A35$59 \&$ btnG $=$.

[19] P. G. Brewer and D. Dyrssen, "Chemical Oceanography of the Persian Gulf," Prog. Oeeanog, vol. 14, no. 5529, pp. 41-55, 1985.

[20] C. Sheppard, M. Al-husiani, F. Al-Jamali et al., "The Gulf: A young sea in decline," Mar. Pollut. Bull., vol. 60, no. 1, pp. 13-38, 2010, doi: 10.1016/j.marpolbul.2009.10.017.

[21] N. P. Nezlin, I. G. Polikarpov, and F. Al-yamani, "Satellite-measured chlorophyll distribution in the Arabian Gulf: Spatial, seasonal and inter-annual variability," Int. J. Ocean. Oceanogr., vol. 2, no. 1, pp. 139-156, 2007, [Online]. Available: https://scholar.google.com/scholar_lookup?title=Satellite-measured chlorophyll distribution in the Arabian Gulf\%3A Spatial\%2C seasonal and inter-annual variability\&author=N.P. Nezlin\&publication_year=2007.

[22] J. E. O’Reilly, S. Maritorena, B. G. Mitchell et al., "Ocean color chlorophyll algorithms for SeaWiFS," J. Geophys. Res. Ocean., vol. 103, no. C11, pp. 24937-24953, 1998, doi: 10.1029/98JC02160.

[23] J. O'Reilly, S. Maritorena, D. A. Siegel et al., "SeaWiFS Postlaunch Calibration and Validation Analyses, Part 3," 2000.

[24] D. A. Siegel, S. Maritorena, N. B. Nelson, M. J. Behrenfeld, and C. R. McClain, "Colored dissolved organic matter and its influence on the satellite-based 
characterization of the ocean biosphere," Geophys. Res. Lett., vol. 32, no. 20, pp. 1-4, 2005, doi: 10.1029/2005GL024310.

[25] F. Al-Yamani, M. Saburova, and I. Polikarpov, "A preliminary assessment of harmful algal blooms in Kuwait's marine environment," Aquat. Ecosyst. Health Manag., vol. 15, no. sup1, pp. 64-72, 2012, doi: 10.1080/14634988.2012.679450.

[26] J. Zhao, M. Temimi, S. Al Kitbi, and N. Mezhoud, "Monitoring HABs in the shallow Arabian Gulf using a qualitative satellite- based index," Int. J. Remote Sens., vol. 37, no. 8, pp. 1937-1953, 2016, doi: 10.1080/01431161.2016.1165886.

[27] I. Polikarpov, F. Al-Yamani, and M. Saburova, "Remote Sensing of Phytoplankton Variability in the Arabian / Persian Gulf," in Remote Sensing of the Asian Seas, V. Barale and M. Gade, Eds. Springer, 2019, pp. 485-501, doi: 10.1007/978-3-319-940670 .

[28] F. Al-Yamani, J. Bishop, E. Ramadhan, M. Al-Husaini, and A. Al-Ghadban, Oceanographic Atlas of Kuwait's waters, 1st ed. KISR, 2004.

[29] G. C. Feldman, "Suomi-NPP/VIIRS," Nasa, 2020. oceancolor.gsfc.nasa.gov/data/viirssnpp/ (accessed Sep. 30, 2020).

[30] S. C. Gallegos, M. D. Lewis, R. W. Gould et al., "Inter-Comparison between VIIRS and MODIS Radiances and Ocean Color Data Products over the Chesapeake Bay," Remote Sens., vol. 7, pp. 2193-2207, 2015, doi:10.3390/rs70202193.

[31] G. C. Feldman, "Chlorophyll a (chlor_a)," Nasa, 2020. https://oceancolor.gsfc.nasa.gov/atbd/chlor_a/ (accessed Sep. 30, 2020).

[32] T. Hattab, C. Jamet, C. Sammari, and S. Lahbib, "Validation of chlorophyll- $\alpha$ concentration maps from Aqua MODIS over the Gulf of Gabes (Tunisia): comparison between MedOC3 and OC3M bio-optical algorithms," Int. J. Remote Sens., vol. 34, no. 20, pp. 7163-7177, 2013, doi: 10.1080/01431161.2013.815820.

[33] S. L. Shang, Q. Dong, C. M. Hu, G. Lin, Y. H. Li, and S. P. Shang, "On the consistency of MODIS chlorophyll- $a$ products in the northern South China Sea," Biogeosciences, vol. 11, no. 2, pp. 269-280, 2014, doi: 10.5194/bg-11-269-2014.

[34] R. J. W. Brewin, D. E. Raitsos, Y. Pradhan, and I. Hoteit, "Comparison of chlorophyll in the Red Sea derived from MODIS-Aqua and in vivo fluorescence," Remote Sens. Environ., vol. 136, pp. 218-224, 2013, doi: https://doi.org/10.1016/j.rse.2013.04.018.

[35] M. Kahru, R. M. Kudela, C. R. Anderson, M. Manzano-Sarabia, and B. G. Mitchell, "Evaluation of satellite retrievals of ocean chlorophyll- $a$ in the california current," Remote Sens., vol. 6, no. 9, pp. 8524-8540, 2014, doi: 10.3390/rs6098524.

[36] T. Pokavanich, Y. Alosairi, R. D. Graaff et al., "THREE-DIMENSIONAL HYDROENVIRONMENT CHARACTERIZATION AND MODELING OF THE NORTHERN ARABIAN GULF," Coast. Eng. Proc., no. 2014, 2014, doi: 10.9753/icce.v34.management.41.

[37] J. R. Hunter, "The physical oceanography of the Arabian Gulfs: a review and theoretical interpretation of previous observations," in Marine Environment and Pollution, Proceedings of the First Arabian Gulf Conference on Environment and Pollution, 1983, pp. 1-23. 
[38] W. E. Johns, F. Yao, and D. B. Olson, "Observations of seasonal exchange through the Straits of Hormuz and the inferred heat and freshwater budgets of the Persian Gulf," $J$. Geophys. Res., vol. 108, no. C12, p. 3391, 2003, doi: 10.1029/2003JC001881.

[39] F. Al-Yamani and S. W. A. Naqvi, "Chemical oceanography of the Arabian Gulf," Deep Sea Res. Part II Top. Stud. Oceanogr., vol. 161, pp. 72-80, 2019, doi: https://doi.org/10.1016/j.dsr2.2018.10.003.

[40] R. B. Husar, M. Prospero, and L. L. Stowe, "Characterization of tropospheric aerosols over the oceans with the NOAA advanced very high resolution radiometer optical thickness operational product," J. QF Geophys. Res., vol. 102, no. D14, pp. 1688916909, 1997.

[41] I. Polikarpov, M. Saburova, and F. Al-Yamani, "Diversity and distribution of winter phytoplankton in the Arabian Gulf and the Sea of Oman," Cont. Shelf Res., vol. 119, pp. 85-99, 2016, doi: https://doi.org/10.1016/j.csr.2016.03.009.

[42] K. A. Kvenvolden and C. K. Cooper, "Natural seepage of crude oil into the marine environment," Geo-Mar Lett, no. 23, pp. 140-146, 2003, doi: 10.1007/s00367-0030135-0.

[43] J. A. Albanai, A GIS Science Simulation for the Expected Sea Level Rise Scenarios on Failka Island in The State of Kuwait, 1st ed. Kuwait: Center For Research and Studies on Kuwait, 2019.

[44] R. Misak, S. Mahfoz, and T. Alasfour, Desert Environment on The State of Kuwait. Center For Research and Studies on Kuwait, 2003 (In Arabic).

[45] Dames and Moore, "Aquatic biology investigations. Studies for Sabiya area, Kuwait Bay and development of electrical networks," Kuwait, 1983.

[46] F. El-Baz and M. Al-Sarawi, Atlas of State of Kuwait From Satellite Images, 1st ed. Kuwait Foundation for the Advancement of Sciences (KFAS), 2000.

[47] C. Hu, Z. Lee, and B. Franz, "Chlorophyll a algorithms for oligotrophic oceans : A novel approach based on three-band reflectance difference," J. Geophys. Res., vol. 117, no. November 2011, pp. 1-25, 2012, doi: 10.1029/2011JC007395.

[48] D. D'Alimonte and G. Zibordi, "Phytoplankton determination in an optically complex coastal region using a multilayer perceptron neural network," IEEE Trans. Geosci. Remote Sens., vol. 41, no. 12, pp. 2861-2868, Dec. 2003, doi: 10.1109/TGRS.2003.817682.

[49] C. J. Willmott, "ON THE VALIDATION OF MODELS," Phys. Geogr., vol. 2, no. 2, pp. 184-194, 1981, doi: 10.1080/02723646.1981.10642213, doi: 10.1080/02723646.1981.10642213.

[50] C. Zhang, C. Hu, S. Shang et al., "Bridging between SeaWiFS and MODIS for continuity of chlorophyll- $a$ concentration assessments off Southeastern China," Remote Sens. Environ., vol. 102, no. 3, pp. 250-263, 2006, doi: https://doi.org/10.1016/j.rse.2006.02.015.

[51] M. Marrari, C. Hu, and K. Daly, "Validation of SeaWiFS chlorophyll a concentrations in the Southern Ocean: A revisit," Remote Sens. Environ., vol. 105, no. 4, pp. 367-375, 2006, doi: https://doi.org/10.1016/j.rse.2006.07.008. 
[52] D. F. Watson and G. M. Philip, "A Refinement of Inverse Distance Weighted Interpolation," Geoprocessing, vol. 2, no. 4, pp. 315-327, 1985, [Online]. Available: https://www.semanticscholar.org/paper/A-refinement-of-inverse-distance-weightedWatson/05460f45dedb446b391889138aef84074986aead.

[53] V. Chaplot, F. Darboux, H. Bourennane, S. Leguédois, N. Silvera, and K. Phachomphon, "Accuracy of interpolation techniques for the derivation of digital elevation models in relation to landform types and data density," Geomorphology, vol. 77, pp. 126-141, 2006, doi: 10.1016/j.geomorph.2005.12.010.

[54] J. P. Musashi, H. Pramoedyo, and R. Fitriani, "Comparison of Inverse Distance Weighted and Natural Neighbor Interpolation Method at Air Temperature Data in Malang Region," CAUCHY - J. Mat. MURNI DAN Apl., vol. 5, no. 2, pp. 48-54, 2018.

[55] D. Coleman, "Mann Whitney Testing with Minitab," 2015. https://www.leansigmacorporation.com/mann-whitney-testing-with-minitab/ (accessed May 12, 2020).

[56] S. C. Doney, "Plankton in a warmer world," Nature, vol. 444, no. 7120, pp. 695-696, 2006, doi: 10.1038/444695a.

[57] W. Sunda, "Feedback Interactions between Trace Metal Nutrients and Phytoplankton in the Ocean," Front. Microbiol., vol. 3, p. 204, 2012.

[58] K. Hayase and N. Shinozuka, "Vertical distribution of fluorescent organic matter along with AOU and nutrients in the equatorial Central Pacific," Mar. Chem., vol. 48, no. 3, pp. 283-290, 1995, doi: https://doi.org/10.1016/0304-4203(94)00051-E.

[59] A. Wirasatriya, Kunarso, L. Maslukah, A. Satriadi, and R. D. Armanto, "Different responses of chlorophyll- $a$ concentration and Sea Surface Temperature ( SST ) on southeasterly wind blowing in the Sunda Strait," in IOP Conf. Series: Earth and Environmental Science 139, 2018, pp. 1-7, doi: doi :10.1088/1755-1315/139/1/012028. 